Alma Mater Studiorum - Università di Bologna DEPARTMENT OF ECONOMICS

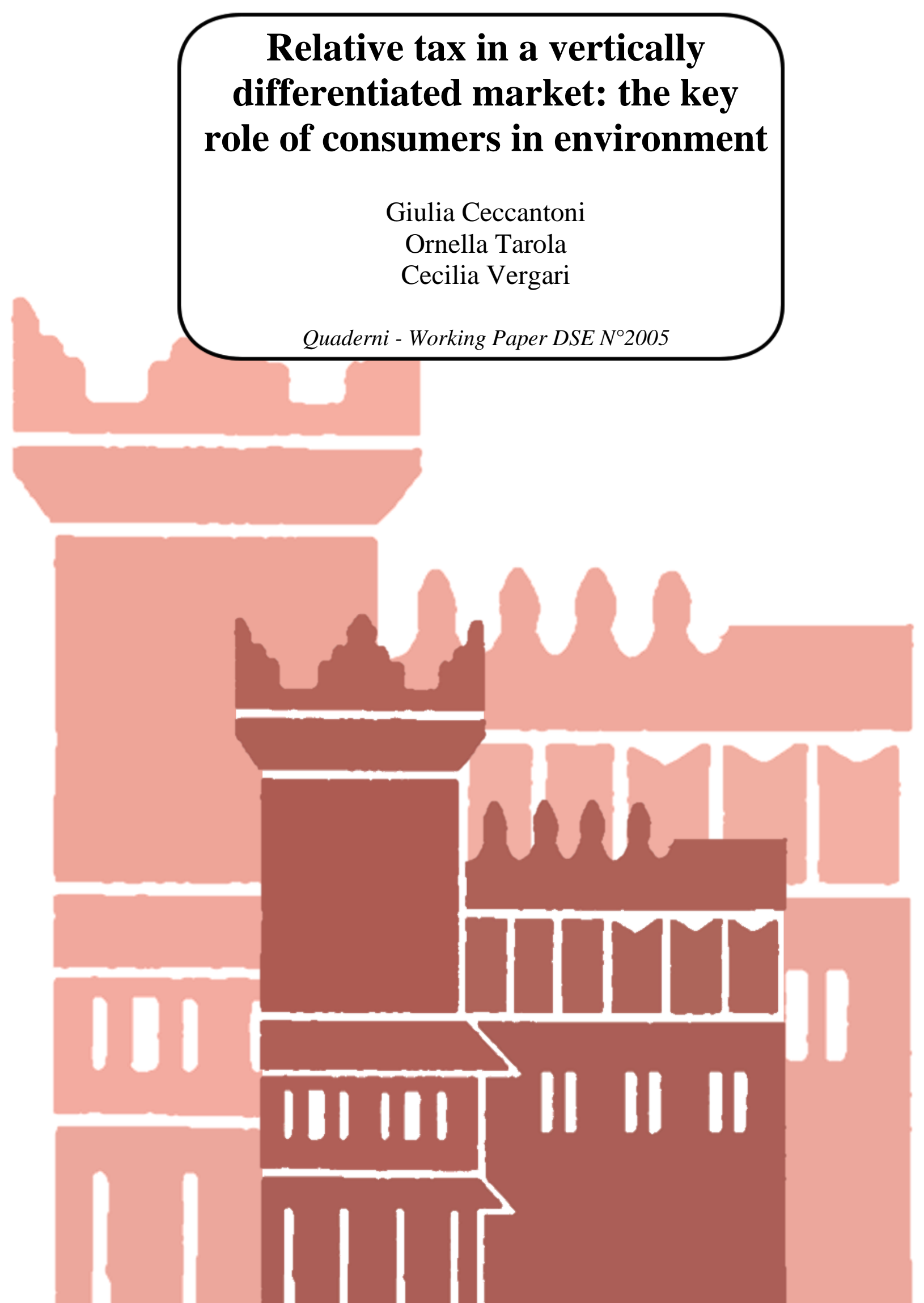




\title{
Relative tax in a vertically differentiated market: the key role of consumers in environment +
}

\author{
Giulia Ceccantoni ${ }^{\mathrm{a}}$, Ornella Tarola $^{\mathrm{b}}$, Cecilia Vergari $^{\mathrm{c}}$ \\ ${ }^{a}$ Memotef, Sapienza University, Via del Castro Laurenziano 9, 00161 Roma, Italy. \\ ${ }^{b}$ Disse, Sapienza University, Piazzale Aldo Moro 5, 00185 Roma, Italy. \\ ${ }^{\mathrm{c}}$ Department of Economic Sciences, University of Bologna, Piazza Scaravilli 2,
}

I-40126 Bologna, Italy.

May 21, 2017

\begin{abstract}
In this paper, under the assumption that green consumption has (at least partially) a social/psychological dimension, we analyse the effect of a carbon tax when it is imposed on consumers buying dirty products rather than on polluting firms. The amount of the tax paid is determined by the share of brown consumers in the market and the quality gap between variants. We show that this tax can abate emissions without inducing the undesirable relocation effect which can be observed in the case when a unilateral climate policy is imposed on polluting producers.
\end{abstract}

JEL classification: H30, D43, Q5, L13.

Keywords: Environmental quality, Vertical differentiation, Duopoly taxation, Consumer behaviour.

\footnotetext{
${ }^{\dagger}$ E-mail addresses: cecilia.vergari@unibo.it (Cecilia Vergari), ornella.tarola@uniroma1.it (Ornella Tarola), giulia.ceccantoni@uniroma1.it (Giulia Ceccantoni). We thank Oscar Amerighi, Rico Maggi, Francesca Sanna-Randaccio and seminar audience at IRE Universit della Svizzera italiana, Lugano $\mathrm{CH}$ for useful comments on a previous draft. The usual disclaimer applies.
} 


\section{Introduction}

"Barack Obama's efforts to join a global carbon emissions pact encountered determined Republican opposition on Capitol Hill. To disarm that resistance requires several things: an acceptance that human-made global warming exists; overcoming an aversion to new taxes, and assurance that American businesses will not be disadvantaged against foreign competitors" (Financial Times, February 2017).

In this paper, we analyse the effect of a carbon tax when (i) it is imposed on consumers rather than on firms, and (ii) it increases with the pool of brown consumers and quality differential between a green and a brown product.

There is an open debate both in EU and in US about possible losses and benefits deriving from an Environmental Fiscal Reform (EFR) and, in particular, on the opportunity of using carbon taxes. Supporters of carbon taxes argue that they could incentivize green behaviour and, thus, spread environmentally friendly habits among producers and consumers. Further, since these taxes are based on the so called polluter pays principle such that the economic agents who are responsible for damaging the environment should suffer the cost related to their behaviour, they comply with efficiency and equity requirements. The opponents of carbon taxes point out however that, under carbon taxes, firms tend to transfer the higher costs of production on consumers, thereby missing the equity requirement. Further, and even worse, these taxes undermine the competitiveness of carbon intensive industries and can induce relocation and carbon leakage effects. ${ }^{1}$ Not even they accept the idea, somehow related to the so called Porter hypothesis, that a fiscal reform could change polluting producers into leaders in clean technologies; or that the high price of polluting good would induce people to find less expensive and energy efficiency products thus promoting a green consumption behavior among people. In case of relocation, no incentive to invest in green innovation would be provided to firms and green habits are not yet significantly widespread.

The empirical evidence on relocation and carbon leakage effects is mixed. Still, the theoretical arguments against carbon taxes cannot be easily denied and can

\footnotetext{
${ }^{1}$ Carbon leakage takes place when a unilateral climate policy aimed at abating emissions in a region/country determines an increase in emissions in another region. See Sanna-Randaccio et al. (2016) for a discussion on the short-term and long-term drivers of this phenomenon. See also Böhringer et al. (2017) for a recent theoretical contribution on anti-leakage measures.
} 
fuel skepticism about the effectiveness of these taxes in abating emissions without penalizing industries' competitiveness.

We do not reject these arguments but advance the hypothesis that they can inspire a different public policy where consumers rather than firms are the direct recipients of carbon taxes, which are mainly intended as a fiscal tool to shift consumers from brown to green consumption habits.

The theoretical argument underlying our formal approach is that brown consumption is not only a source of pollution but also and mainly a social phenomenon. A large strand of literature shows that consumers are partially driven in their consumption choice by some social norms which define rules of behavior and interactions among individuals (Ostrom, 2000; Carlsson et al., 2010; Mantovani et al. 2017). These norms, which are enforced by internalized feelings and/or social sanctions (Elster, 1989), when concerned with environmental issues, state that green consumption is a habit displayed by good citizens. Accordingly, while buying clean products, people feel to comply with a norm of worthy citizenship and, thus, obtain a social/psychological benefit of social approval and self-esteem. Along the same rationale, they suffer a social stigma when purchasing dirty products. ${ }^{2}$

To the extent that green goods are used by consumers/citizens to get a social status (the status of good citizens), green consumption turns out to be a conspicuous practice. Typically, conspicuous goods (Veblen, 1899) are chosen by consumers with the main aim to exhibit their wealth or other specific characteristics so that they can distinguish themselves from others. ${ }^{3}$ As immediate by-product, the social prestige associated with the consumption of a good increases with the distance between this good and the ones bought by other consumers: driving an expensive car (like Rolls Royce or Bentley) confer a higher social benefit to the driver, the cheaper the cars driven by the others; fashion designer clothes meet the aim to show that the person who wears them is rich to the extent the others wear items which are out of style. In a similar vein, since environmentally friendly products are intended by consumers as a means to advertise their socially worthy behavior and, thus, obtaining social ap-

\footnotetext{
${ }^{2}$ In line with this argument, Owen and Videras (2007) and Videras et al. (2012) argue that individuals who are more willing to behave according to civic and cultural norms and have more social ties are also more willing to protect a public good, namely, the natural environment, while Brekke et al. (2003) and Czajkowski et al. (2015) show that self image is central to recycling behavior.

${ }^{3}$ We refer the interested reader to Mantovani et al. (2017) for an in-depth discussion on the positional content of green goods.
} 
proval, the social benefit that consumers obtain when buying green good is affected by the environmental quality distance between variants. Namely, the contribution coming from green consumers to protect the environment is relatively more valuable, the cleaner the goods they buy compared with the brown products. Along the same rationale, the dirtier the relative brown quality, the larger the damage that brown consumers inflict to the environment and, thus, the worst their social image. It is as if the conspicuous dimension of consumption beget a correspondence between the environmental quality ladder in the market and the social ladder in the social community: the lower the environmental quality along the quality ladder, the lower the ranking of the buyer along the social ladder. In our approach, the public policy is shaped by this correspondence so that the social stigma penalizing the socially blameworthy citizens (namely brown consumers) is immediately translated into taxes which increase with the environmental quality gap.

Empirical evidence finds, however, that the effectiveness of the social dimension as a driver of green consumptions depends on the share of brown consumers. When few consumers decide to buy green products, the social stigma attached to not doing it may be weak, since the dirty behavior is rather widespread and, thus, somehow accepted as a common practice. In this circumstance, the social incentive to a responsible behavior turns out to be low. The results emerged from OPOWER, one of the largest randomized field experiments in history, tend to confirm this statement. OPOWER sent people home energy report letters, providing a comparison between their energy usage and that of their neighbors. Also, customers obtained energy conservation tips. OPOWER ran a program for 23 utilities, including 6 of the largest 10 utilities in the USA and 600,000 households. From the study, it emerged that the intervention reduced average energy demand by $1.11 \%$ to $2.78 \%$ from the baseline usage (Allcott, 2011). Similar findings are obtained by Carlsson et al. (2010) when considering conformity in green consumption between males and females in Sweden. Their findings are that the proportion of consumers choosing environmentally friendly coffee over standard coffee plays a significant and positive role in women's willingness-to-pay for environmentally friendly coffee. Welsch and Kuhling (2009) find that, in Germany, the use of solar thermal systems, the subscription to green electricity and the purchase of organic food are all three affected by the consumption patterns of reference persons. Salazar et al. (2013) analyse the role of social pressure on consumption among students, lecturers and administrative personnel in a university in the Netherlands. Individuals provided with information 
about their peers' choice are three times more likely to 'buy' a sustainable product than those acting without this information.

Moreover, whenever brown consumption habits are widespread, the environmental damage turns out to be an urgent and particularly significant problem since emissions increase with the polluting goods which are in the market. So, there exists a twofold reason why carbon taxes should increase with the set of consumers buying brown goods: the larger this set, the weaker the social pressure against brown attitude and the more relevant the environmental damage.

We argue that carbon taxes can mimic the social pressure thereby counterbalancing the possible weakness of social norms and, thus, containing the damage generated by brown consumption. Brown consumers get less socially/psychologically frustrated when observing that their unresponsible behavior is rather widespread. Accordingly, we relate taxes to the share of brown consumers in the market. The larger this share, the higher the corresponding taxes that brown consumers pay: as the social stigma induced by the norms runs down so that the environmental damage increases with the diffusion of brown consumption, the fiscal penalty gets stronger.

\section{The modeling framework}

Formally, we adopt a model of vertical product differentiation with two firms providing goods with different emission intensities per unit of production to a population of consumers: the high quality variant has lower emission intensity per unit of production than the low quality product. Consumption is assumed to have a social/psychological dimension so as to capture the above evoked correspondence between the quality ladder in the market and the social ladder in the community where people live. This dimension is exploited by the policy maker to design a consumer-targeted fiscal policy where a monetary punishment (taxes) is inflicted to blameworthy people buying the dirty variant, depending on the share of brown consumers and the quality gap between variants. ${ }^{4}$

In a two stage game, with firms competing at the first stage in environmental quality and at the second stage in price, we define the equilibrium configuration of the market under the assumption that a policy maker taxes dirty consumers (Section 3). Since the quality differential is determined by the quality choice of firms, equilibrium taxes are endogenously found, with firms contributing to fix their

\footnotetext{
${ }^{4}$ Although the relevance of social rewards in providing incentives to those who perform activities with positive externalities is well known in the literature (see, e.g., Arrow, 1970), to the best of our knowledge it has never been exploited to define a fiscal environmental policy.
} 
amount. Then, we wonder how this equilibrium would change in the case the tax were imposed on the brown producer (Section 4).

Although several arguments have been recently developed against energy subsidies, they have been so far largely used worldwide, either as direct cash transfers to producers and consumers, or as indirect support tools, such as tax exemptions and rebates. ${ }^{5}$ Accordingly, we also describe an alternative scenario where the policy maker subsidies green consumers and compare the effectiveness of consumer-based taxes vsus subsidies (Section 5). Interestingly, our results are robust to alternative assumptions of the model (Section 6)

We find that a consumer-targeted fiscal measure is always preferred over a firmbased fiscal measure in terms of incentive to green innovations and, in most cases, reduction of pollution damage. Interestingly, firms are never penalized by the fiscal plan when it is targeted to consumers. At the opposite, when taxes are imposed on the brown producer, they reduce firms' profits and thus open the door to the possibility of firms' relocation. Moreover, and rather surprisingly, although a subsidy never determines a reduction in profits, it may be environment detrimental, in the case when it is granted to the green producer rather than to green consumers, since it may increase total emissions in the market.

Finally, when comparing taxes and subsidies on consumers, under relative tax the brown producer has a higher incentive to improve his/her environmental quality and emissions can be lower. For example, in the case when a Government introduces a rather low tax, or a massive fiscal intervention is planned in a country where the green producer is highly environmentally virtuous, then a relative tax should be preferred over a relative subsidy, since the former would reduce emissions more than the latter. An immediate environmental policy implication is that the effectiveness of fiscal plans - and their main effects on environment - changes with the features (such as the state of the art technology) of the industry or country where it is realized.

\section{Our paper in the literature}

Our analysis complements the literature on the effects of different environmental policies on the equilibrium configurations when consumers are willing to pay more for less polluting goods (see Cremer and Thisse, 1999; Moraga-Gonzalez and PadronFumero, 2002; Bansal and Gangopadhyay, 2003;inter alia). The entry point of

\footnotetext{
${ }^{5}$ See Gerlagh et al., (2009); Galinato and Yoder, (2010), inter alia, for a theoretical appraisal of the opportunity of using taxes or subsidies.
} 
this literature is that products are equivalent in all characteristics but one: the environmental quality. This attribute is ranked in the same way by all consumers so that an environmentally friendly goods is ranked higher than a brown product along a quality ladder. Thus, in a model of vertical product differentiation where a green good is the high quality variant, with the brown alternative representing the low quality one, this literature compares the effects of government policies, which are typically intended as taxes/subsidies or minimum quality standards, when they are imposed on firms. ${ }^{6}$

We extend this literature along two research lines. First, we assume that the policy maker attributes a social content to green consumption and defines the environmental policy accordingly. In order to relate the social dimension of green consumption to the environmental policy, we borrow some ingredients from Ben Elhadj and Tarola (2015). Starting from the idea that people seek a relative position among peers and buy products, at least partially, for their social value, they introduce in a vertically differentiated setting the notion of consumers' relative preferences for environmentally friendly products. These preferences link the utility from buying a product to the relative position along the social ladder that this product can confer to the buyer. ${ }^{7}$ In our model, this relative dimension of consumers' contribution represents one of the key ingredients of the government policy which is also shaped by the share of brown consumers in the market. It is worth noting that this relative dimension puts our paper particularly close to Lombardini-Riipinen (2005) where, in a vertically differentiated market with an ad valorem tax on firms, a subsidy is paid to green consumers depending on the quality gap between variants. ${ }^{8}$

Secondly, we describe the market equilibrium under the assumption that a fiscal policy is targeted to consumers rather than firms and observe how this equilibrium would change in the traditional setting of firm-based policies when taking into ac-

\footnotetext{
${ }^{6} \mathrm{~A}$ remarkable exception is Koonsed (2015) that considers an excise tax on consumers and a subsidy for green consumers.

${ }^{7}$ The rationale underlying our analysis is that when buying green goods, consumers get a social satisfaction behind the utility traditionally observed: this satisfaction increases with the quality gap between green and brown products, as this gap determines the relative contribution of green consumers to environment protection and thus their social position among peers. The role of relative preferences for environmental goods are also analysed by Mantovani et al., (2016), and Mantovani and Vergari, (2017), in a framework where the social content of a green good may be in contrast with its intrinsic performance.

${ }^{8}$ In Lombardini-Riipinen (2005) this subsidy is however unrelated to the pool of consumers buying one of the two variants existing in the market.
} 
count the social content of green consumerism. ${ }^{9}$

Also, we are somehow related to the literature concerned with the Porter hypothesis. Contrary to the conventional wisdom according to which a stringent regulation can reduce profits, Porter (1991) argues that environmental regulations can enhance green investment thereby generating in the long run gains that can counterbalance the costs faced to satisfy them. ${ }^{10}$ In our analysis, we show that a fiscal plan can induce firms to increase the quality of their products with positive effects on the equilibrium profits. Further, we discuss how these effects change, depending on the nature of the plan (subsidy vsus tax) and the agent to which the plan is targeted (consumers vsus firm).

Finally, we contribute to the debate on the incentive to relocate manufacturing activities under unilateral climate policy. In a large strand of theoretical research, several arguments are found both in favour and against the possible shift of domestic activities abroad due to unilateral carbon taxes and the empirical literature provides mixed evidence (Petrakis and Xepapadeas, 2003; Ikefuji et al., 2016; Sanna Randaccio et al., 2016). We discuss here how the possible incentive to relocation changes with the recipients of carbon tax - consumers vsus producer - and try to emphasize the reason for this finding to hold.

\section{The model}

Consider an uncovered vertically differentiated market with two firms $H$ and $L$ producing two variants of the same good, namely $u_{H}$ and $u_{L}$. Variants are homogeneous in terms of hedonic quality but they are vertically differentiated in terms of polluting emissions. Without loss of generality, variant $u_{H}$ is assumed to pollute less than variant $u_{L}$ so that the former (resp. latter) variant will be referred to as high (resp. low) quality variant, with $u_{H}>u_{L} \cdot{ }^{11}$

When producing, firms incur quality-specific fixed production cost $F_{i}$. This cost can be viewed as a cost of installing new machineries and equipment, or a cost

\footnotetext{
${ }^{9}$ To the best of our knowledge, defining an environmental policy on the basis of this social content represents a novel approach in the policy oriented literature of environmentally economics.

${ }^{10}$ See on the Porter hypothesis Xepapadeas and de Zeeuw, (1999); André et al., (2009) inter alia. See also Lambertini (2013) for an in-depth review of the Porter hypothesis in the literature.

${ }^{11}$ In our model, like in Rodriguez-Ibeas (2007), Garcìa-Gallego and Georgantzís (2009) and Andrè et al. (2009), we follow the traditional approach of vertical differentiation as in Mussa and Rosen (1978) and Gabszewicz and Thisse (1979) so that the variable $u_{i}$ mirrors the environmental quality $i$.
} 
of technology adoption. As a such, it is typically assumed to be sunk when the production starts. ${ }^{12}$ The cost associated with the cleaner variant $u_{H}$ is greater than that associated with the dirtier product $u_{L}$, so $F_{H}>F_{L}$. From a theoretical viewpoint, this type of cost enables to abstract from any supply-side issue and, thus, to identify the demand-driven effects of fiscal measures on the equilibrium configuration. Following Andrè et al. (2009) and without any loss of generality, we assume that $F_{L}=0$. Also, in spite of $F_{H}>0$, our assumption is that the quality level $u_{H}$ is so high to guarantee that equilibrium profits of firm $H$ are non negative. Thus, we drop this cost from the equilibrium analysis for the sake of simplicity. We discuss in Section 6 whether our findings are robust to an alternative and somehow more traditional specification where costs are strictly convex in quality. ${ }^{13}$

Consumers are uniformly distributed in the interval $[0, \beta]$ with density $\frac{1}{\beta}$ and characterized by the intensity of their environmental concern $\theta$. Since the parameter $\theta$ is proportional to the willingness to pay (henceforth WTP) for environmental quality, at $\theta=\beta$ the WTP is maximal. Each consumer is supposed to buy at most one unit of variant which ensures to her the highest utility except if the alternative of no purchase is better.

We analyse the following two-stage game. First, firms choose the optimal quality of their variant along the spectrum of the technologically feasible quality, given by the interval $\left[u_{\min }, \bar{u}\right]$ where $u_{\min }>0$ represents the minimal quality required and $\bar{u}$ the highest achievable quality according to the state of the art technology. Second, they compete in prices. Then, we characterize market equilibrium configuration.

\section{Carbon tax and brown consumption}

We consider a scenario where brown consumption is taxed. The tax $T$ depends on the quality gap between variants, $\left(u_{H}-u_{L}\right)$, and the share of the dirty consumers, $x_{L}^{t}$. The idea underlying this modeling strategy is as follows. The tax represents a monetary punishment for socially blameworthy consumers, namely, those consumers that buying brown goods contribute to damage the environment. Since a dirty behavior is relatively more detrimental, the cleaner is the green variant, this tax is modeled by taking into account the quality gap between variants. Further, in order to be effective in counterbalancing the diffusion of a brown attitude, this tax tends

\footnotetext{
${ }^{12}$ See on this Frondel et al.(2007) and Mantovani et al. (2017).

${ }^{13}$ Fixed costs are convex for example in Moraga-Gonzalez and Padron-Fumero (2002), Lombardini-Riipinen (2005), Brécard, (2013).
} 
to increase with the share of brown consumers. ${ }^{14}$

Accordingly, $T=t\left(u_{H}-u_{L}\right) x_{L}^{t}$, with $t$ being the tax rate and $t \in(0,1)$, appears as a negative component in the utility function of brown consumers.

Notice that this punishment changes with the distance between qualities along the environmental quality ladder. As a such, it can be viewed as a relative tax. Further, since the optimal quality $u_{i}$, with $i=H, L$, is endogenously found, the actual punishment $T$ is endogenous and depends on the equilibrium choices of firms. This reconciles the public dimension of the fiscal plan with a market-based mechanism: the monetary punishment inflicted to brown consumers is partially determined by firms, which increase the environmental quality of their products due to the consumers' attitude toward green and brown goods.

Formally, we define the indirect utility function from buying the brown variant $u_{L}$ as follows: ${ }^{15}$

$$
U_{L}(\theta)=\theta u_{L}-p_{L}-T .
$$

A standard utility function of vertical differentiation is instead assumed for green consumers, namely:

$$
U_{H}(\theta)=\theta u_{H}-p_{H} .
$$

The indifferent consumer between the low quality variant and not buying at all, say $\theta_{L}^{t}$, is given by

$$
\theta_{L}^{t}\left(\theta_{H}^{t}\right)=\frac{p_{L}+t\left(u_{H}-u_{L}\right) \theta_{H}^{t}}{t\left(u_{H}-u_{L}\right)+u_{L}}
$$

where $\theta_{H}^{t}$ represents the indifferent consumer between the two variants. This indifferent consumer $\theta_{H}^{t}$ is found from the following indifferent condition:

$$
\theta_{H}^{t} u_{H}-p_{H}=\theta_{H}^{t} u_{L}-p_{L}-t\left(u_{H}-u_{L}\right)\left(\theta_{H}^{t}-\frac{p_{L}+t\left(u_{H}-u_{L}\right) \theta_{H}^{t}}{t\left(u_{H}-u_{L}\right)+u_{L}}\right)
$$

\footnotetext{
${ }^{14}$ This tax can also capture the differential between the emissions observed due to the socially blameworthy behaviour of consumers $x_{L}^{t}$ buying the brown variant and the emissions which would be observed if the brown consumers $x_{L}^{t}$ bought the green variant $u_{H}$. The former are proportional to $u_{L} x_{L}^{t}$ while the latter to $u_{H} x_{L}^{t}$. In this alternative view, this emissions differential $\left[x_{L}^{t} u_{H}-u_{L} x_{L}^{t}\right]$ enables to contrast the potential contribution that brown consumers could give to the environment and the actual damage caused by their blameworthy behavior. Thus, it somehow provides a correspondence between the social stigma which condemns this attitude along a social dimension and its fiscal punishment along a monetary dimension, thereby representing an economic measure of this socially irresponsible behaviour.

${ }^{15}$ At first sigh, this formalization recalls a network effect like in Brécard (2013). We discuss in Section 6 the difference between her approach and ours.
} 
which is satisfied at

$$
\theta_{H}^{t}=\frac{\left(u_{L}+t u_{H}-t u_{L}\right) p_{H}-p_{L} u_{L}}{\left(u_{H}-u_{L}\right)\left(u_{L}+t u_{H}\right)} .
$$

From (4), we get that:

$$
\theta_{L}^{t}=\frac{p_{L}+t p_{H}}{u_{L}+t u_{H}}
$$

Notice that the above consumers' maximization problem is solved by assuming rational expectations about the size of the brown market share. Indeed, when optimally choosing their variant, consumers take the decisions of the others as given and, assuming rational expectations, at equilibrium the expected demand of brown consumers coincides with its actual value. Assuming that both firms are active in the market, that is, $\theta_{L}^{t}<\theta_{H}^{t}<\beta$, demand functions are then, ${ }^{16}$

$$
x_{H}^{t}=\beta-\theta_{H}^{t}, x_{L}^{t}=\theta_{H}^{t}-\theta_{L}^{t} .
$$

We solve the game by backward induction, thereby analysing, first, the price stage and, then, moving to the quality stage.

At the price stage, firms maximize the following profit functions:

$$
\pi_{H}^{t}\left(p_{H}, p_{L}\right)=x_{H}^{t}\left(p_{H}, p_{L}\right) p_{H} \text { and } \pi_{L}^{t}\left(p_{H}, p_{L}\right)=x_{L}^{t}\left(p_{H}, p_{L}\right) p_{L} .
$$

By solving the system of BRs, we find the pair of candidate equilibrium prices $p_{i}\left(u_{i}, u_{j}\right), i, j=H, L$ and $i \neq j$ as well as demands that we plug into the profit functions. Next, solving for quality competition, we find the following result.

Lemma 1. The equilibrium qualities are $\tilde{u}_{H}^{t}=\bar{u}$ and $\tilde{u}_{L}^{t}=\frac{2}{7} \bar{u}\left(1-t+\sqrt{5 t+t^{2}+1}\right)$.

Proof. The profit function of the green producer is monotonically increasing in $u_{H}$. Given this, we obtain the optimal value of the brown variant from standard maximization of $\pi_{L}\left(\bar{u}, u_{L}\right)$ wrt $u_{L}$.

The equilibrium prices $\tilde{p}_{i}^{t}$ and the corresponding market shares $\tilde{x}_{i}^{t}$ of firms $H$ and $L$ are, respectively:

$$
\begin{aligned}
& \tilde{p}_{H}^{t}=\frac{1}{4} \bar{u} \beta \text { and } \tilde{p}_{L}^{t}=\frac{1}{28} \bar{u} \beta\left(\sqrt{t^{2}+5 t+1}-t+1\right) \\
& \tilde{x}_{H}^{t}=\frac{7}{12} \beta \text { and } \tilde{x}_{L}^{t}=\frac{7}{12} \frac{\beta\left(1+\sqrt{t^{2}+5 t+1}-t\right)}{3 t-2 \sqrt{t^{2}+5 t+1}(t-1)+2 t^{2}+2} .
\end{aligned}
$$

\footnotetext{
${ }^{16}$ We then verify that, indeed, at equilibrium, these conditions are satisfied, that is, the market is an uncovered duopoly. This is our starting point in all scenarios analysed in the paper.
} 
Notice that the optimal quality $\tilde{u}_{L}^{t}$ chosen by the dirty producer and the corresponding price $\tilde{p}_{L}^{t}$ increase with the tax, while the equilibrium market share $\tilde{x}_{L}^{t}$ decreases. The market share of the cleaner producer $\tilde{x}_{H}^{t}$ is instead unaffected by the tax. The rationale for the above findings can be captured as follows. On the one hand, the optimal brown quality increases with the tax. This would enlarge, ceteris paribus, the market share of the dirty producer. Still, the corresponding price of the brown variant $p_{L}^{t}$ increases with the tax, too. This raise pushes away from the market some low-income consumers, which would have been willing to buy the dirty variant at some lower price $\tilde{p}_{L}<\tilde{p}_{L}^{t}$, but refrain from buying at this high equilibrium price. On the other hand, consumers purchasing the cleaner variant are completely unaffected by the presence of the tax: the tax moves upward the optimal quality of the brown variant and this would induce some consumers buying the green good to switch to the brown alternative, ceteris paribus. This switch, however, is refrained by the high price of the brown good. As a result of these two contrasting forces, the equilibrium market share of the green producer does not react to the tax. Not even the equilibrium price $\tilde{p}_{H}^{t}$ of the green variant changes with the tax. Although the optimal price of the brown variant increases with this fiscal measure and prices are strategic complements, the quality gap between variant $\left(\tilde{u}_{H}^{t}-\tilde{u}_{L}^{t}\right)$ at equilibrium decreases with $t$. Since the lower is the quality gap, the fiercer is the price competition, the green firm does not find it optimal to change its equilibrium price, which accordingly does not vary with the tax.

Finally, taxation does not determine any effect on both equilibrium profits that write as:

$$
\begin{aligned}
& \tilde{\pi}_{H}^{t}=\frac{7}{48} \bar{u} \beta^{2}, \\
& \tilde{\pi}_{L}^{t}=\frac{1}{48} \bar{u} \beta^{2} .
\end{aligned}
$$

When considering this result in the light of the debate on the relocation effects which are possibly induced by a unilateral carbon tax, it immediately emerges that no penalty is suffered by firms, which accordingly do not find any incentive to relocate. ${ }^{17}$ It is worth noticing that this result departs from those which are typically observed when a traditional carbon tax is introduced in a market. ${ }^{18}$ Moreover, as it will be shown in the next section, the same argument cannot be extended to

\footnotetext{
${ }^{17}$ Indeed, formally, the equilibrium profits defined in (5) and (6) correspond to those under the baseline scenario à la Choi and Shin (1992), in the absence of policy intervention.

${ }^{18}$ In our setting, we contrast a "traditional carbon tax", intended as a fixed tax on emissions and a relative carbon tax, whose actual weight depends on the quality differential.
} 
a relative tax imposed on the brown producer. In that case, relocation incentives emerge.

In order to capture the effect of this tax on global emissions, we define pollution damage as:

$$
\tilde{E}^{t}=\tilde{E}_{H}^{t}+\tilde{E}_{L}^{t}
$$

with $\tilde{E}_{i}^{t}=\left(u^{0}-u_{i}^{t}\right) x_{i}^{t}, i=\{H, L\}$ and the parameter $u^{0}$ representing the zero emission quality. ${ }^{19}$ Notice that, by definition, $u^{0} \geq \bar{u}$. So, it may happen that the emission-free quality benchmark is not available in the market and thus $u^{0}>\bar{u} .{ }^{20}$ At equilibrium, total damage writes:

$$
\tilde{E}^{t}=\frac{1}{12} \beta \frac{8 u^{0} t+u^{0}\left(\sqrt{5 t+t^{2}+1}-1\right)-9 \bar{u} t}{t},
$$

with $\frac{\partial \tilde{E}^{t}}{\partial t}<0$ given that the average environmental quality increases, while the brown production as well as total production decrease with $t$.

We gather our findings as follows.

Proposition 1. The optimal quality of the brown variant increases with the tax on brown consumption, while global emissions decrease. Both equilibrium profits are unaffected by the tax so that an incentive to relocation does not emerge.

\section{Carbon tax: consumption versus production}

We next wonder whether the above results still hold in the more traditional scenario where the fiscal policy is directly levied on firms rather than on consumers.

While keeping that the policy maker designs the fiscal plan based on the social content of green consumerism, we assume here that the brown producer is taxed. So, firm $L$ 's profit writes as $\pi_{L}^{f t}\left(p_{H}, p_{L}\right)=x_{L}^{f t}\left(p_{L}-t\left(u_{H}-u_{L}\right) x_{L}^{f t}\right)$, whereas profit of the green firm is as in a traditional model of vertical differentiation, that is, $\pi_{H}^{f t}\left(p_{H}, p_{L}\right)=x_{H}^{f t} p_{H} \cdot{ }^{21}$ Consumers' preferences are standard, namely $U_{i}=\theta u_{i}-p_{i}$.

\footnotetext{
${ }^{19}$ This function of total emissions resembles the traditional one (see for example LombardiniRiipinen, 2005), where emission differential are weighted for the quantity sold by firms.

${ }^{20}$ This formulation is quite general as it allows us to consider also the case in which $\bar{u}=u^{0}$. Although from a theoretical viewpoint, $\bar{u}=u^{0}$ represents a particular case of our approach, casual observations show that it holds in some sectors. For example, in the automotive sector the electric car is emission-free.

${ }^{21}$ Superscript $f t$ stands for firm-based tax.
} 
As a result, the indifferent consumers between buying good $L$ and not buying at all, and between buying good $L$ and good $H$, are, respectively:

$$
\theta_{L}^{f t}=\frac{p_{L}}{u_{L}}, \theta_{H}^{f t}=\frac{p_{H}-p_{L}}{u_{H}-u_{L}}
$$

Demands for the goods, assuming an uncovered duopoly, are then: $x_{L}^{f t}=\theta_{H}^{f t}-\theta_{L}^{f t}$ and $x_{H}^{f t}=\beta-\theta_{H}^{f t}$.

Price competition leads to the following second stage prices:

$$
\begin{aligned}
p_{H}^{f t}\left(u_{H}, u_{L} ; t\right) & =\frac{2 \beta u_{H}\left(u_{H}-u_{L}\right)\left(u_{L}+t u_{H}\right)}{u_{L}\left(4 u_{H}-u_{L}\right)+2 t u_{H}\left(2 u_{H}-u_{L}\right)}, \\
p_{L}^{f t}\left(u_{H}, u_{L} ; t\right) & =\frac{\beta u_{L}\left(u_{H}-u_{L}\right)\left(u_{L}+2 t u_{H}\right)}{u_{L}\left(4 u_{H}-u_{L}\right)+2 t u_{H}\left(2 u_{H}-u_{L}\right)} .
\end{aligned}
$$

with the corresponding second stage demands and profits being:

$$
\begin{aligned}
x_{L}^{f t}\left(u_{H}, u_{L} ; t\right) & =\beta u_{H} \frac{u_{L}}{u_{L}\left(4 u_{H}-u_{L}\right)+2 t u_{H}\left(2 u_{H}-u_{L}\right)}, \\
x_{H}^{f t}\left(u_{H}, u_{L} ; t\right) & =2 \beta u_{H} \frac{u_{L}+t u_{H}}{u_{L}\left(4 u_{H}-u_{L}\right)+2 t u_{H}\left(2 u_{H}-u_{L}\right)}, \\
\pi_{L}^{f t}\left(u_{H}, u_{L} ; t\right) & =\frac{\beta^{2} u_{L}^{2}\left(u_{H}-u_{L}\right)\left(u_{L}+t u_{H}\right) u_{H}}{\left(-u_{L}^{2}+4 u_{H} u_{L}+4 t u_{H}^{2}-2 t u_{H} u_{L}\right)^{2}}, \\
\pi_{H}^{f t}\left(u_{H}, u_{L} ; t\right) & =\frac{4 \beta^{2} u_{H}^{2}\left(u_{H}-u_{L}\right)\left(u_{L}+t u_{H}\right)^{2}}{\left(-u_{L}^{2}+4 u_{H} u_{L}+4 t u_{H}^{2}-2 t u_{H} u_{L}\right)^{2}} .
\end{aligned}
$$

Solving for quality competition, we derive the following result. ${ }^{22}$

Lemma 2. The equilibrium qualities are $u_{H}^{f t}=\bar{u}$ and $u_{L}^{f t}=\tilde{u}_{L}^{f t} \operatorname{such} Q^{f t}(t)=\frac{\tilde{u}_{L}^{f t}}{\bar{u}} \in$ $\left(\frac{4}{7}, 0.691\right)$.

Proof. See Appendix (8.1.1).

Finally, pollution damage under relative tax on the brown firm writes as:

$$
\begin{aligned}
\widetilde{E}^{f t}= & \left(u^{0}-\bar{u}\right) 2 \beta \bar{u} \frac{\tilde{u}_{L}^{f t}+t \bar{u}}{\tilde{u}_{L}^{f t}\left(4 \bar{u}-\tilde{u}_{L}^{f t}\right)+2 t \bar{u}\left(2 \bar{u}-\tilde{u}_{L}^{f t}\right)} \\
& +\left(u^{0}-\tilde{u}_{L}^{f t}\right) \beta \bar{u} \frac{\tilde{u}_{L}^{f t}}{\tilde{u}_{L}^{f t}\left(4 \bar{u}-\tilde{u}_{L}^{f t}\right)+2 t \bar{u}\left(2 \bar{u}-\tilde{u}_{L}^{f t}\right)} .
\end{aligned}
$$

Since $\frac{\partial \tilde{E}}{\partial t}^{f t}<0$, we can conclude that this policy is always effective in reducing the pollution damage.

Nonetheless, from direct comparisons, the following holds:

\footnotetext{
${ }^{22}$ We check that for any $\left(u_{H}, u_{L}\right)$, second stage equilibrium prices are such that $0<\theta_{L}<\theta_{H}<\beta$.
} 
Proposition 2. A relative tax on brown consumers is more effective than a tax on the brown producer (i) in terms of incentive to innovate and (ii) whenever the cleaner variant is not extremely green, in terms of emissions reduction. Moreover, in contrast with the tax on brown consumers, (iii) a tax on the brown producer reduces the equilibrium profit of the brown firm at the benefit of the green one.

Proof. See Appendix (8.1.2).

Interestingly, the firm-based tax is less effective in terms of quality improvement. At first glance, this result is counterintuitive since, under tax on brown consumers, the fiscal policy affects firms' decision in an indirect way. The intuition lies on the fact that when the tax is levied on consumers, it decreases their willingness to pay for the low environmental quality. Since the disadvantage suffered by the brown rival is stronger, the larger is the quality gap, the incentive to increase the quality of the dirty variant and thus contrasting this penalty turns out to be stronger in this scenario than in the alternative one where consumers' willingness to pay is unaffected.

As for the pollution damage, numerical simulations show that whenever the ratio $\frac{\bar{u}}{u^{0}}$ is sufficiently small, that is, the green variant is quite far from being emission-free, then $\tilde{E}^{t}<\widetilde{E}^{f t}$, whereas the contrary holds for $\frac{\bar{u}}{u^{0}}$ sufficiently high. In particular, for any $t$, the emissions coming from the green firm are lower under consumer tax than under firm tax, i.e. $\tilde{E}_{H}^{t}<\tilde{E}_{H}^{f t}$, because $\tilde{x}_{H}^{t}<\tilde{x}_{H}^{f t}$ and the high environmental qualities are equal, $\tilde{u}_{H}^{t}=\tilde{u}_{H}^{f t}=\bar{u}^{23}$ As for the emissions coming from the brown firm, although the comparison is a priori ambiguous because both the low environmental quality and quantity are larger under consumer tax than under firm tax $\left(\tilde{u}_{L}^{t}>\tilde{u}_{L}^{f t}\right.$ and $\tilde{x}_{L}^{t}>\tilde{x}_{L}^{f t}$ ), numerical simulations show that $\tilde{E}_{L}^{t}>\tilde{E}_{L}^{f t}$. So, $\tilde{E}_{H}^{t}<\tilde{E}_{H}^{f t}$ but $\tilde{E}_{L}^{t}>\tilde{E}_{L}^{f t}$. Whenever $\frac{\bar{u}}{u^{0}}$ is small, so that $\frac{\bar{u}}{u^{0}}<\hat{u}(t)$, the former component prevails over the latter and determines $\tilde{E}^{t}<\tilde{E}^{f t}$. On the contrary, when $\frac{\bar{u}}{u^{0}}$ tends to its maximal level $1, \tilde{E}^{t}>\tilde{E}^{f t}$ since the latter component prevails. ${ }^{24}$

Finally, regarding the producer surplus, we observe that both firms prefer the scenario where consumers are taxed rather than the alternative case in which the tax is imposed on the brown producer. Indeed, it holds that $\tilde{\pi}_{H}^{t}-\pi_{H}^{f t}\left(u_{H}, u_{L} ; t\right)>0$ and especially $\tilde{\pi}_{L}^{t}-\pi_{L}^{f t}\left(u_{H}, u_{L} ; t\right)>0 .{ }^{25}$ More precisely, under tax on consumers,

\footnotetext{
${ }^{23}$ Notice that $\tilde{x}_{i}^{f t}$, with $i=H, L$, denotes the equilibrium quantity, namely $\tilde{x}_{i}^{f t}=x_{i}^{f t}\left(\bar{u}, \tilde{u}_{L}^{f t}\right)$.

${ }^{24}$ In particular, when the green variant is emission-free $\left(\frac{\bar{u}}{u^{0}}=1\right)$, it only matters the damage coming from the brown firm. In this case, we observe that $\tilde{E}^{t}>\tilde{E}^{f t}$, for any $t$.

${ }^{25}$ In the Appendix (8.1.3), we show that, given $u_{H}=\bar{u}$, these inequalities hold for any $u_{L}$ and
} 
$\tilde{x}_{H}^{t}$ and $\tilde{p}_{H}^{t}$ are independent of $t$, whereas under tax on the brown firm $\tilde{x}_{H}^{f t}$ and $\tilde{p}_{H}^{f t}$ increase with $t$; however, it always holds that $\tilde{p}_{H}^{t}>\tilde{p}_{H}^{f t}$ and $\tilde{x}_{H}^{f t}>\tilde{x}_{H}^{t}$. As for the low quality good, both quantities $\tilde{x}_{L}^{t}$ and $\tilde{x}_{L}^{f t}$ decrease and both prices $\tilde{p}_{L}^{t}$ and $\tilde{p}_{L}^{f t}$ increase with $t$. However, it always holds that $\tilde{x}_{L}^{t}>\tilde{x}_{L}^{f t}$ and $\tilde{p}_{L}^{t}<\tilde{p}_{L}^{f t}$. Overall, the high quality firm prefers the consumer tax scenario because the larger price in this scenario overcompensates the lower quantity; the same preference holds for the brown firm: now, the larger quantity overcompensates the lower price. Notice that, as the per-unit tax on the brown producer increases, the profit of the brown firm decreases, thus entailing the traditional and unpleasant effect of reducing firms' profits and providing an incentive to relocation.

Before concluding, we would like to consider whether taxing brown consumers penalizes them more than the traditional measure of a tax which is targeted to polluter producers. ${ }^{26}$ From a direct comparison between consumers' surplus in each scenario, it emerges that this surplus of brown consumers is higher when the tax is directly levied on consumers rather than on firms. Indeed, under consumers-based tax, the quantity is larger and the corresponding price is lower than under firmsbased tax. Rather surprisingly, the surplus of green consumers is lower under the former scenario (consumers-based tax) than under the latter, in spite of $\tilde{x}_{H}^{f t}>\tilde{x}_{H}^{t}$. This has to be attributed to the price gap $\left(\tilde{p}_{H}^{t}-\tilde{p}_{H}^{f t}\right)>0$. Accordingly, the brown consumers, which could a priori represent the more damaged social category in the case of a brown consumption tax, do not suffer in this case more than in the alternative one, where tax is imposed on the brown producer. Further, ad hoc redistributive policies can be undertaken with the primary goal to compensate the possible harm inflicted to them.

\section{Carbon tax or green subsidies?}

So far, we have pointed out that taxing consumption rather than production can be preferred from several points of view. For the sake of completeness, in the following we briefly analyse and compare the effect of a subsidy, when it is either granted to green consumers or to the green producer.

so, a fortiori, for the equilibrium $u_{L}=\widetilde{u}_{L}^{f t}$.

${ }^{26}$ We relegate to the Appendix (8.1.3) formal details on this. 


\subsection{Subsidy and green consumption}

In line with the previous setting, the subsidy $S$ depends on the quality gap between variants and the share of the dirty consumers, $x_{L}^{s}$. It represents a monetary reward for socially worthy consumers, namely those consumers that buying green goods contribute to protect the environment and it writes as:

$$
S=s\left(u_{H}-u_{L}\right) x_{L}^{s}
$$

where $s$ indicates the subsidy rate, $s \in(0,1)$. This subsidy appears as a positive component in the utility function of the green consumers, which is, accordingly:

$$
U_{H}(\theta)=\theta u_{H}-p_{H}+S,
$$

while the utility of consumer type $\theta$ when buying the brown variant is left unaffected by this policy and it writes as

$$
U_{L}(\theta)=\theta u_{L}-p_{L}
$$

The indifferent consumer between buying the brown variant and refraining from buying is, as in a standard model, $\theta_{L}^{s}=\frac{p_{L}}{u_{L}}$. As for the choice between the two variants, consumer type $\theta$ buys the green variant $H$ if and only if

$$
\theta u_{H}-p_{H}+s\left(u_{H}-u_{L}\right) x_{L}^{s}>\theta u_{L}-p_{L} .
$$

Denote $\theta_{H}^{s}$ the consumer type that is indifferent between buying the brown and the green variant so that, assuming, as before, that both firms are active in the market, $x_{L}^{s}=\theta_{H}^{s}-\theta_{L}^{s}$ and $x_{H}^{s}=\beta-\theta_{H}^{s}$. The indifferent consumer among the two variants is then such that

$$
\theta_{H}^{s} u_{H}-p_{H}+s\left(u_{H}-u_{L}\right)\left(\theta_{H}^{s}-\theta_{L}^{s}\right)=\theta_{H}^{s} u_{L}-p_{L} \Longleftrightarrow \theta_{H}^{s}=\frac{p_{H} u_{L}-p_{L} u_{L}+s p_{L} u_{H}-s p_{L} u_{L}}{(s+1)\left(u_{H}-u_{L}\right) u_{L}} .
$$

Firms' profits are then $\pi_{i}^{s}\left(p_{i}, p_{j}\right)=x_{i}^{s}\left(p_{i}, p_{j}\right) p_{i}$, with $i, j=H, L$ and $j \neq i$.

We solve the game by backward induction. So, starting from the price stage, we then move to the quality competition thereby solving for the optimal qualities. ${ }^{27}$

Lemma 3. The equilibrium qualities are $\tilde{u}_{H}^{s}=\bar{u}$ and $\tilde{u}_{L}^{s}=\bar{u} \frac{s+4}{s+7}$.

Proof. The profit function $\pi_{H}^{s}\left(u_{H}, u_{L}\right)$, is monotonically increasing in $u_{H}$. Given this, $\tilde{u}_{L}^{s}$ follows from standard maximization of $\pi_{L}^{s}\left(\bar{u}, u_{L}\right)$.

\footnotetext{
${ }^{27}$ The formal solution of the game is standard and follows the same reasoning as in Section (3). Details are available upon request.
} 
Thus, we obtain the corresponding equilibrium variables: ${ }^{28}$

$$
\begin{aligned}
& \tilde{p}_{H}^{s}=\bar{u} \beta \frac{s+1}{s+4} \text { and } \tilde{p}_{L}^{s}=\frac{1}{2} \bar{u} \beta \frac{s+1}{s+7}, \\
& \tilde{x}_{H}^{s}=\frac{1}{3} \beta \frac{s+7}{s+4} \text { and } \tilde{x}_{L}^{s}=\frac{1}{6} \beta \frac{s+7}{s+4}, \\
& \tilde{\pi}_{H}^{s}=\frac{1}{3} \bar{u} \beta^{2}(s+1) \frac{s+7}{(s+4)^{2}} \text { and } \tilde{\pi}_{L}^{s}=\frac{1}{12} \bar{u} \beta^{2} \frac{s+1}{s+4} .
\end{aligned}
$$

Both equilibrium prices and the optimal quality of the more polluting firm $\tilde{u}_{L}^{s}$ increase with the subsidy rate $s$, while the equilibrium market share of each producer decrease with $s$. Indeed, the subsidy induces the dirty firm to improve the quality of its variant. This immediately affects the corresponding equilibrium price $\tilde{p}_{L}^{s}$ which, indeed, turns out to be higher, the higher is the subsidy rate. Since prices are strategic complements, the higher is the equilibrium price $\tilde{p}_{L}^{s}$, the higher is the equilibrium price of the rival $\tilde{p}_{H}^{s}$. At these high prices, however, firms serve less consumers than in the framework without subsidy. The positive effect of the subsidy on equilibrium profits develops along these price driver and market share driver with the former prevailing over the latter. The reduction of both quantities, joint with the increase in the brown environmental quality, also explains why subsidizing green consumption is always effective in reducing emissions, which formally write as

$$
\tilde{E}^{s}=\frac{1}{2} \beta \frac{7 u^{0}-6 \bar{u}+\left(u^{0}-\bar{u}\right) s}{s+4},
$$

with $\frac{\partial \tilde{E}^{s}}{\partial s}<0$.

These results come with no surprise since subsidying consumers increase their willingness to pay. It is by far more questionable whether this subsidy has to be preferred over the tax. Indeed, while both fiscal instruments escape from the unpleasant relocation effect, it is not clear which one is more effective in terms of environmental protection (and possibly in terms of incentive to innovate) while the former calls for financial resources that, in principle, could be burdened by all citizens, the carbon tax is targeted to brown consumers and it induces tax revenues.

From comparing the equilibrium configurations emerging under subsidy and tax on consumption, by assuming that $t=s$, we can state the following. Define:

$$
\breve{u}(t) \equiv \frac{1}{3 t^{2}}\left(2 t^{2}-4-11 t+(4+t) \sqrt{5 t+t^{2}+1}\right)
$$

with $\breve{u}(t)<0$ for any $t<\bar{t}$ with $\bar{t}=0.88316$.

\footnotetext{
${ }^{28}$ We check that at this equilibrium the market is an uncovered duopoly.
} 
Proposition 3. When considering consumers-based fiscal measures, emissions under tax are lower than the corresponding ones under subsidy whenever the cleaner variant is sufficiently green, namely $\frac{\bar{u}}{u^{0}}>\breve{u}(t)$. Since $\breve{u}(t)<0$ for any $t<\bar{t}$, then $\frac{\bar{u}}{u^{0}}>\breve{u}(t)$ always holds whenever the fiscal measure is not extremely significant. Further, the optimal quality of the brown variant is higher under relative tax than under subsidy, so that $\tilde{u}_{L}^{t}>\tilde{u}_{L}^{s}$.

Proof. See Appendix (8.2.1).

The rationale underlying the effectiveness of the subsidy compared to the tax in reducing emissions, is that, for $s=t$, the market share of the green producer is larger under tax than under subsidy, namely $\tilde{x}_{H}^{t}>\tilde{x}_{H}^{s}$, while the reverse holds for the market share of brown producer, so that $\tilde{x}_{L}^{s}>\tilde{x}_{L}^{t} \cdot{ }^{29}$ Thus, the net effect on global emissions depends on the relative contribution of every component. ${ }^{30}$ In particular, only when a Government plans a massive fiscal intervention $(t \geq \bar{t})$ in a country where the green producer is not so environmentally virtuous, then a relative subsidy should be preferred over a relative tax from an environmental viewpoint, since the former would reduce emissions more than the latter. In this case however, there exists a trade-off between advancements in green technologies and emissions abatement: the subsidy is more effective only with respect to latter goal while being dominated by the tax with respect to the other. ${ }^{31}$

\subsection{Subsidy and green production}

We finally consider the effect of the subsidy on the environment when it is targeted to the green firm, as it is quite often observed in reality.

\footnotetext{
${ }^{29} \mathrm{~A}$ larger demand from the low income consumer is faced under subsidy, in spite of the higher price of the dirty variant $\left(\tilde{p}_{L}^{s}>\tilde{p}_{L}^{t}\right)$. Indeed, the price gap under subsidy is larger than the corresponding gap under tax. Thus, the dirty variant is relatively cheaper under subsidy than under tax. It immediately follows that, ceteris paribus, some consumers, buying under tax the green variant, prefer to buy under subsidy the dirty variant with an immediate expansion of the equilibrium market share for the dirty producer.

${ }^{30}$ The incentive to improve the quality of the dirty variant is always higher under a relative tax than under a relative subsidy. Accordingly, ceteris paribus, the damage determined by the brown producer is by far less significant in the case of tax than in the alternative scenario with the subsidy.

${ }^{31}$ In Appendix (8.2.2), we also compare consumers and producers surplus under these two scenarios.
} 
To this aim, we introduce the relative subsidy in the firm $H$ 's profit which, thus, writes as $\pi_{H}^{f s}\left(p_{H}, p_{L} ; s\right)=x_{H}^{f s}\left(p_{H}+s\left(u_{H}-u_{L}\right) x_{L}^{f s}\right)$. Firm $L$ 's profit is $\pi_{L}^{f s}\left(p_{H}, p_{L} ; s\right)=$ $x_{L}^{f s} p_{L}$. Demands are $x_{L}^{f s}=\theta_{H}^{f s}-\theta_{L}^{f s}$ and $x_{H}^{f s}=\beta-\theta_{H}^{f s}$, where the indifferent consumer types are defined as in (8).

Proceeding backwards, we first analyse price competition and then, solving for quality competition, we characterize the equilibrium configuration. The optimal qualities are:

$$
\widetilde{u}_{H}^{f s}=\bar{u} \text { and } \widetilde{u}_{L}^{f s}=\bar{u} \frac{3 s+4}{5 s+7}
$$

with $\widetilde{u}_{L}^{f s}$ being increasing in $s$, while the equilibrium prices and market shares are

$$
\begin{aligned}
& \tilde{p}_{H}^{f s}=\beta \bar{u} \frac{s+1}{3 s+4} \text { and } \tilde{p}_{L}^{f s}=\frac{1}{2} \beta \bar{u} \frac{s+1}{5 s+7}, \\
& \tilde{x}_{H}^{f s}=\frac{1}{2} \beta(s+2) \frac{5 s+7}{(2 s+3)(3 s+4)} \text { and } \tilde{x}_{L}^{f s}=\frac{1}{2} \beta(s+1) \frac{5 s+7}{(2 s+3)(3 s+4)} .
\end{aligned}
$$

The equilibrium profits write as: ${ }^{32}$

$$
\tilde{\pi}_{H}^{f s}=\frac{1}{2} \beta^{2} \bar{u} \frac{(s+1)(s+2)^{2}(5 s+7)}{(2 s+3)(3 s+4)^{2}} \text { and } \tilde{\pi}_{L}^{f s}=\frac{1}{4} \bar{u} \beta^{2} \frac{(s+1)^{2}}{(2 s+3)(3 s+4)} .
$$

Finally, we get the equilibrium pollution damage

$$
\widetilde{E}^{f s}=\frac{1}{2} \beta \frac{7 u^{0}-6 \bar{u}+5 s u^{0}-4 s \bar{u}}{3 s+4} .
$$

Thus, we can state the following

Proposition 4. Whenever $\frac{\bar{u}}{u_{0}}>\frac{1}{2}$, (i) a relative subsidy to the green firm is detrimental for the environment. Further, even in the case when the firm-based fiscal plan reduces pollution, subsidising green consumers is more effective than subsidising the green producer in terms of (ii) incentive to innovate and (iii) emissions reduction.

Proof. See Appendix (8.2.3).

So, rather surprisingly, subsidying the green firm can raise emissions in the market. A relative subsidy to the cleaner producer raises the optimal quality of the dirty variant, its price and profit $\left(\frac{\partial \tilde{p}_{L}^{f s}}{\partial s}>0, \frac{\partial \tilde{\pi}_{L}^{f s}}{\partial s}>0\right)$. It also raises the price and profit of the green firm $\left(\frac{\partial \tilde{p}_{H}^{f s}}{\partial s}>0, \frac{\partial \tilde{\pi}_{H}^{f s}}{\partial s}>0\right)$. Nonetheless, it reduces the green firm market share at the benefit of the brown firm market share $\left(\frac{\partial \tilde{x}_{L}^{f s}}{\partial s}>0, \frac{\partial \tilde{x}_{H}^{f s}}{\partial s}<0\right)$

\footnotetext{
${ }^{32}$ We check that at this equilibrium, the market is an uncovered duopoly.
} 
because both prices increase with the subsidy rate, but $\tilde{p}_{H}^{f s}$ increases more than $p_{L}^{f s}$ (formally $\frac{\partial \tilde{p}_{H}^{f s}}{\partial s}>\frac{\partial \tilde{p}_{L}^{f s}}{\partial s}$ ). As a consequence, some consumers shift from the green to the brown variant, with an ambiguous effect on pollution damage. In particular, when the green variant is extremely clean $\left(\frac{\bar{u}}{u_{0}}>\frac{1}{2}\right)$, the reduction in emissions from the green production is not very significant, so that the increase in the emissions coming from the brown firm overcompensates the corresponding reduction from the green production. ${ }^{33}$

Interestingly, the firm-based subsidy is dominated also in terms of quality improvement. In order to soften the disadvantage suffered under consumption subsidy, the brown firm raises the quality of the dirty variant and thus contrasting this penalty turns out to be stronger in this scenario than in the alternative one where consumers' willingness to pay is unaffected. ${ }^{34}$

\section{Discussion of our main assumptions}

Our analysis has been conducted under two key assumptions. First, we have considered the adoption of relative fiscal measures: the tax and the subsidy are related to the emissions differential between goods. The second assumption regards production costs that we have assumed to be quality-specific but non-increasing in quality.

We next discuss these assumptions and we provide, with some formal details, some intuitions on how they could be relaxed.

\subsection{Relative fiscal policy}

We have modelled the fiscal incentives as a function of relative emissions: the differential between the pollution caused by the brown consumers and the pollution which would be observed if these consumers had adopted a socially responsible behaviour, buying the cleaner variant. Our modelling strategy resembles a sort of network effect because, formally, consumers' preferences also depend on what the others purchase. However, in our approach, the share of brown consumers that appear in the utility function only measures the (relative) contribution of socially blameworthy behav-

\footnotetext{
${ }^{33}$ This happens, for instance, when the green variant is emission-free, namely $\bar{u}=u^{0}$. In this extreme case, only the increase in the brown firm's emissions takes place with no reduction of emissions by the green firm.

${ }^{34}$ In the Appendix (8.2.4), we also compare consumer and producer surplus under these two scenarios.
} 
ior on which the (relative) fiscal policy is tailored. As extensively motivated in the introduction, these fiscal policies result from exploiting the social/psychological drivers which inspire, at least partially, consumers' environmental concern. ${ }^{35}$ Thus, the monetary punishment/reward increases with the number of brown consumers in order to discourage potential conformity behaviours towards brown consumption (which get stronger with the pool of brown consumers) ${ }^{36}$ as well as to hinder the environmental damage (that expands with the amount of polluting goods).

Although we are not related with this issue, it is worth noticing that in a different perspective, our modeling framework is in line with the so called attitude-behaviour gap . This phenomenon is well documented by the literature (Carrington et al., 2010; Greendex, 2014): on the one hand, consumers declare to be willing to pay a price premium for buying environmentally friendly goods; on the other hand, these declarations do not translate into green purchases so that the market share of green products is still rather small. ${ }^{37}$ In our approach, tax is somehow related to the contribution that brown consumers could give to the environment when translating their declaration about green products into actual behavior - thus generating emissions which are proportional to $x_{L}^{t} u_{H}$ - and the one which they actually give when buying the brown product - with emissions which are proportional to $x_{L}^{t} u_{L}$.

Contributions investigating environmental quality competition and taxation in the presence of green network effects (like Brécard, 2013, and Greaker and Midttømme, 2016) lay, instead, on the assumption that consumers benefit from an increase in the number of consumers buying the same environmental variant.

In our approach, the consequence of such relative policies, that depend on the quality gap, is that their effect on quality competition is amplified with respect to a fixed fiscal measure. Indeed firms, and in particular the more polluting firm, are

\footnotetext{
${ }^{35}$ From the 2014 Greendex Report, it emerges that consumers' environmental awareness is no longer restricted to more advanced countries, being rather diffused even in middle-income economies, such as India and China, and less developed countries such as South Korea, Brazil, and Argentina. It is also found that "consumers who already display behavior that is relatively sustainable and are told that their behavior is above average from an environmental point of view are more motivated to improve their behavior further than are consumers who display less sustainable habits." (2014 Greendex Report, 3).

${ }^{36}$ See Grilo et al. (2001) for the effects of conformity in consumer behavior on market competition.

${ }^{37}$ While an increasing number of consumers declares to be concerned with environmental issues, data show a significant inconsistency between these declared attitudes and consumers' actual behaviour (Finisterra et al., 2009; Gupta and Ogden, 2009).
} 
induced to improve its environmental quality here, not only for the subsidy or tax per se, but with the primary purpose of affecting its overall absolute value. ${ }^{38}$

Finally, let us briefly notice that these fiscal policies could be relatively easily implemented. An example of a market where the relative tax can be applied is the automotive sector. In this sector, manufacturers have to secure the approval of specific emission standards passing particular tests, so that governments could easily collect data about vehicles' emissions. Indeed, in several countries, they already did, as documented by different environmental campaigns launched by public authorities that, basically, rank vehicles according to their environmental impact. ${ }^{39}$ As for the market share of traditional versus electric/hybrid vehicles, data at European level are collected, for instance, by the European Automobile Manufacturers Association (see http://www.acea.be/). Another industrial sector characterized by an increasing environmental concern is agriculture, where organic food is acquiring increasing importance in terms of production and consumption in comparison with conventional agriculture. Different studies show that organic as compared with conventional agriculture is characterized by a lower environmental impact in terms of, for instance, preserving biodiversity, and in terms of fossil energy and water consumption. ${ }^{40}$ Since 1991, with Council Regulation (EEC) No 2092/913 now replaced by Council Regulation (EC) No 834/2007 on organic production and labelling of organic products, the organic sector has been included in EU policies. According to this regulation, organic products and services have to meet the EU Ecolabel requirements and Member States are supposed to provide the statistical information

\footnotetext{
${ }^{38}$ Consider a scenario such that consumers' preferences are:

$$
\begin{aligned}
U_{H}(\theta) & =\theta u_{H}-p_{H}+d S, \text { if buys } H, \\
U_{L}(\theta) & =\theta u_{L}-p_{L}+g T, \text { if buys } L,
\end{aligned}
$$

with $d=0$ and $g=1$ in the tax scenario whereas $d=1$ and $g=0$ in the subsidy scenario; $S \in(0,1)$ and $T \in(0,1)$ defined as a fixed (per-unit) subsidy and tax to green and brown consumers, respectively. It is possible to show that such fiscal measures are at most slightly effective at improving the quality in the market with respect to a baseline scenario à la Choi and Shin (1992) with no policy intervention.

${ }^{39} \mathrm{See}$, for instance, the Italian guidelines on $\mathrm{CO}_{2}$ emissions, www.mit.gov.it/mit/site.php? $\mathrm{p}=\mathrm{cm} \& \mathrm{o}=\mathrm{vd} \& \mathrm{id}=2724$; the EPA Smart Way Program in the US, www.epa.gov/smartway/basic-info/index.htm; the Australian Green Vehicle Guide, http://www.greenvehicleguide.gov.au/GVGPublicUI/home.aspx.

${ }^{40}$ See, among others, the report at

http://www.isprambiente.gov.it/files/biodiversita/8Agricolturabiologica.pdf as well as Tuomisto et al., (2012) and Mondelaers et al., (2009).
} 
necessary for its implementation and monitoring. Indeed, according to Eurostat data, the organic sector, both in terms of cultivated area and number of organic products, has been rapidly expanding during the past years. ${ }^{41}$

\subsection{Innovation costs}

Our paper is mainly devoted to capture the demand-driven effects of relative fiscal measures on the equilibrium configuration of the market. Accordingly, the assumption of costs which are fixed in quantity, from a theoretical viewpoint, represents a natural entry point for the analysis. So far, we have introduced the simplest quality specific cost structure $F_{i}, i=H, L$. This assumption is rather reasonable when describing sectors where firms incur only cost of technology adoption, as in André et al. (2009). ${ }^{42}$

In line with the literature on abatement effort, we next provide some insights on an alternative specification of costs that are increasing and convex in quality. ${ }^{43}$ Thus, they write as $\frac{u_{H}^{2}}{2}$. We explore the role of these costs when they are only incurred for the green production. ${ }^{44}$

It is worthy noticing that profit function of the brown firm remains unchanged and, in turn, the functional relation between the two variants is unaffected. However, the high quality firm no longer chooses the available top quality in the market, so that, for any given scenario, the average environmental quality decreases.

To check the robustness of our results, by taking into account the above described relations, we have implemented numerical simulation and, thus, obtained the optimal green quality and, hence, the brown quality, both firms' profits and the pollution damage at equilibrium. ${ }^{45}$ As we will show, our main crucial findings are robust to this alternative specification.

\footnotetext{
${ }^{41}$ See the report at http://ec.europa.eu/agriculture/rica/pdf/Organic_2016_web_new.pdf for anindepth overview of the organic agriculture in the European Union.

${ }^{42}$ See André et al. (2009) for further details on this.

${ }^{43}$ This modeling structure can be reconciled with the approach where $u_{i}$ captures the abatement effort of firms. In this alternative perspective the abatement effort affects the emission intensity of goods. Accordingly, the lower the emission intensity per unit of production, the higher the environmental quality of the product. See, for example, Moraga-Gonzalez and Padro-Fumero (2002) and Lombardini-Riipinen (2005). The abatement cost in this literature is convex.

${ }^{44}$ Given the mathematical complexity added to the model with this new assumption, in order to get a comparable intuition, we decided to disregard the costs of brown production.

${ }^{45}$ See the Appendix 8.3 for details on the implementation of the numerical simulations.
} 
The main points of our baseline model hold, as we argue in the following Proposition.

Proposition 5. With convex quality costs, (i) a relative tax on brown consumption improves the environmental quality and reduces global emissions without affecting firms' profits. Comparing this consumption tax with a firm-based tax, in the latter case (ii) the optimal quality of the brown variant is lower; (iii) emissions can be larger; and (iv) the brown firm is damaged. Finally, (v) taxing brown consumption can be more environmental effective than subsidizing green consumption.

Even introducing quality-specific costs which are increasing and convex, we can conclude that a tax on brown consumption can be preferred over a tax on brown production. Indeed, the former induces a larger environmental quality improvement than the latter, i.e., $\tilde{u}_{L}^{t}>\tilde{u}_{L}^{f t}$. Also, whenever $\beta$ takes large values we observe that, for high values of the distance between the optimal green quality and the emissionfree quality $u^{0}$, ceteris paribus, $\tilde{E}^{f t}>\tilde{E}^{t}$. Finally, as for the profits, a relative tax on production, in contrast with a tax on consumption, may induce firms to relocate. ${ }^{46}$

Moreover, when comparing tax on consumption versus subsidy, we confirm that, in line with the baseline model, the former measure can be more effective than the latter. In particular, concerning the environmental quality improvement, under consumer-based fiscal measures, we obtain that for relatively high values of $\beta$, the brown quality is higher under tax, $\tilde{u}_{L}^{t}>\tilde{u}_{L}^{s}$ as in the baseline model. The result is reversed, however that is, $\tilde{u}_{L}^{s}>\tilde{u}_{L}^{t}$, for relatively low values of $\beta$. The intuition for the role of $\beta$ is that when the average WTP for environmental quality is large, it can compensate for the larger quality costs that we observe with respect to the baseline model and things remain qualitatively the same. By contrast, for low values of $\beta$, this compensating effect does not take place and it is the subsidy that, increasing the relative WTP for the green variant induces a larger quality improvement. Finally, when $\frac{\bar{u}}{u^{0}}$ is small, we observe that emissions under subsidy are higher than those observed under tax, namely $\tilde{E}^{s}>\tilde{E}^{t}$. Even this finding is consistent with the analysis in the baseline model.

\footnotetext{
${ }^{46}$ For the sake of completeness, we report in the Appendix 8.3 the remaining scenarios comparisons: subsidy and green consumption versus subsidy and green production.
} 


\section{Conclusions}

We have shown in our analysis that, contrary to what has been somehow argued in the past decades, consumers can play a key role in pollution abatement. In particular, whenever the social content of green consumption is recognized to be an essential driver to consumers' behavior, the policy maker can define a fiscal policy in such a way to pursue, simultaneously, the twofold aim of enhancing green innovation and abating emissions. Rather surprisingly, this ambitious goal can be reached more easily when consumers are the core target of a fiscal measure than in the alternative, and more traditional scenario, where firms are the direct recipients of fiscal tool. While in EU, public opinion is divided on the urgency of facing environmental problems and the risk of causing firms'relocation and thus job losses, under Trump's administration, the debate centers around a conservative climate solution, such as a carbon border tax which could "strengthen our economy, benefit working-class Americans, reduce regulations, protect our natural heritage and consolidate a new era of Republican leadership". In this paper, we have proposed a market-based rationale where firms contribute to determine a monetary reward/ punishment to consumers, while consumers provide firms with the incentive to increase the environmental quality of their goods. Interestingly, although this mechanism is in line with the desirable polluters pay principle, it escapes from the evoked relocation effect since reward and punishment do not depend on the place where goods are produced, being related only to their social content.

We acknowledge that a natural argument against our approach is that in our model the tax is imposed on brown consumers, which traditionally consists of lowincome people. Thus, it penalizes the weakest class in the society. Nonetheless, we argue that our perspective can benefit this class along two different dimensions. First, this tax reduces emissions thereby generating healthy benefits to all citizens. Moreover, quite often, the more polluted areas are the ones where low-income citizens live. Thus, reducing emissions can curb urban blight and, as a consequence, mitigate the environmental degradation which is particularly significant in these areas. Second, the tax revenue generated by this carbon tax can be earmarked for improving the living standards of low-income citizens. For example, tax revenue can (i) consolidate social assistance programs and improve access of low-income families to education and health services, in developing countries; (ii) or reduce regressive tax exemptions and provide some monetary benefits after retirement to the poors with rather short life expectancy, in developed countries. Whatever the redistributive 
policy, our approach opens the door to the possibility of compensating the brown consumers, after taxation.

\section{Appendix}

\subsection{Carbon tax and brown consumption}

\subsubsection{Proof Lemma 2}

Proof. First, we find that $\frac{\partial}{\partial u_{H}} \pi_{H}^{f t}\left(u_{H}, u_{L} ; t\right)>0$, always. The optimal choice of firm $H$ is then $u_{H}^{f t}=\bar{u}$. As for firm $L, \pi_{L}^{f t}$ is concave in $u_{L}$. The first derivative is: $\frac{\partial}{\partial u_{L}} \pi_{L}^{f t}\left(u_{H}, u_{L} ; t\right)>0 \Longleftrightarrow(3 t-7) u_{L}^{3}+2 u_{H}\left(-10 t+t^{2}+2\right) u_{L}^{2}-12 t u_{H}^{2}(t-1) u_{L}+$ $8 t^{2} u_{H}^{3}>0$. Set $\frac{u_{L}}{u_{H}}=Q \in(0,1)$, the sign of the derivative is as the sign of $f(Q, t)$ :

$$
f(Q, t)=(3 t-7) Q^{3}+2 Q^{2}\left(-10 t+t^{2}+2\right)-12 t Q(t-1)+8 t^{2} .
$$

Given the concavity of $\pi_{L}^{f t}$ wrt $u_{L}$ and, in turn, wrt to $Q$, and given that $f\left(\frac{4}{7}, t\right)>0$ and $f(0.691, t)<0$, we can state that there exists a $Q^{f t}(t)=\frac{\widetilde{u}_{L}^{f t}}{\bar{u}} \in\left(\frac{4}{7}, 0.691\right)$ such that $\frac{\partial}{\partial u_{L}} \pi_{L}^{f t}\left(u_{H}, u_{L} ; t\right)>0$ for $Q<Q^{f t}(t), \frac{\partial}{\partial u_{L}} \pi_{L}^{f t}\left(u_{H}, u_{L} ; t\right)=0$ for $Q=Q^{f t}(t)$ and $\frac{\partial}{\partial u_{L}} \pi_{L}^{f t}\left(u_{H}, u_{L} ; t\right)<0$ for $Q>Q^{f t}(t)$.

\subsubsection{Proof of Proposition 2}

Proof. We split the proof in three parts:

(i) Recall that the optimal quality gap in case of tax is levied on brown consumption is: $\frac{\tilde{u}_{L}^{t}}{\bar{u}}=\frac{2}{7}\left(1-t+\sqrt{5 t+t^{2}+1}\right)$. This is increasing and concave in $t$. It takes value $\frac{4}{7}$, which is its minimal value, in $t=0$, it takes value 0.756 in $t=1$. In order to show that $Q^{f t}(t)=\frac{\tilde{u}_{L}(t)}{\bar{u}}<\frac{\tilde{u}_{L}^{t}}{\bar{u}}$, it is sufficient that the sign of (18), computed in $\frac{\tilde{u}_{L}^{t}}{\bar{u}}$, is negative: $f\left(\frac{\tilde{u}_{L}^{t}}{\bar{u}}, t\right)=\frac{8}{343} \sqrt{5 t+t^{2}+1}\left(-32 t^{2}-5 t^{3}+7+30 t\right)+$ $\frac{8}{343}\left(5 t+t^{2}+1\right)^{\frac{3}{2}}(3 t-7)+t(t-1)\left(31 t+2 t^{2}+2\right)<0$. This holds for any $t>0$. (ii) Formally, both damages, $\tilde{E}^{t}$ defined in (7) and $\tilde{E}^{f t}$ defined in (11), are decreasing

and convex in $t$ and they take the same value in the absence of fiscal policy, i.e. in $t=0$ when $\tilde{u}_{L}^{t}=\tilde{u}_{L}^{f t}$. Numerical simulations show: ${ }^{47}$

\footnotetext{
${ }^{47}$ We consider several values for $t \in(0,1)$. For a given $t$ we derive the equilibrium value of $u_{L}=u_{L}^{f t}$ from equation (18) and we compare pollution damages. Details are available upon request from the authors.
} 


$$
\tilde{E}^{t}-\widetilde{E}^{f t}<0 \Longleftrightarrow \frac{\bar{u}}{u^{0}}<\widehat{u}(t),
$$

with $\widehat{u}(t)$ increasing in $t$ and such that $\widehat{u}(t) \in(0.5,0.721)$, where $\widehat{u}(0)=0.5$ and $\widehat{u}(1)=0.721$. Recall from Lemma 2 that $\frac{\widetilde{u}_{L}^{f t}}{\bar{u}}$ takes value equal to $4 / 7$ in $t=0$ and 0.691 in $t=1$.

(iii) Partial derivatives reveal that

$$
\begin{aligned}
& \frac{\partial \pi_{H}^{f t}}{\partial t}=8 \beta^{2} \bar{u}^{3} u_{L}^{2}\left(\bar{u}-u_{L}\right) \frac{u_{L}+t \bar{u}}{\left(-u_{L}^{2}+4 \bar{u} u_{L}+4 t u_{H}^{2}-2 t \bar{u} u_{L}\right)^{3}}>0 \\
& \frac{\partial \pi_{L}^{f t}}{\partial t}=\beta^{2} \bar{u}^{2} u_{L}^{2}\left(\bar{u}-u_{L}\right) \frac{3 u_{L}^{2}-4 \bar{u} u_{L}-4 t u_{H}^{2}+2 t \bar{u} u_{L}}{\left(-u_{L}^{2}+4 \bar{u} u_{L}+4 t \bar{u}^{2}-2 t \bar{u} u_{L}\right)^{3}}<0 .
\end{aligned}
$$

Notice that $\frac{\partial \pi_{H}^{f t}}{\partial t}>0$ and $\frac{\partial \pi_{L}^{f t}}{\partial t}<0$ for any $u_{L}$ and so, a fortiori, for the equilibrium quality $\frac{\widetilde{u}_{L}^{f t}}{\bar{u}} \in\left(\frac{4}{7}, 0.691\right)$

\subsubsection{Consumption tax versus production tax}

When comparing consumers surplus and firms profits, it emerges that, (i) for the high quality segment as well as overall, consumers surplus is higher under relative tax to the brown producer than under tax to brown consumers. In contrast, consumers of the low quality good prefer to be taxed than buying from a taxed (and brown) firm. Finally, (ii) firms are better off when the tax is on brown consumers than on the brown producer.

Proof. (i) Consumers surplus under relative taxation on brown consumption for the high quality segment $\left(\widetilde{C S}_{H}^{t}\right)$, for the low quality segment $\left(\widetilde{C S}_{L}^{t}\right)$ and overall $\left(\widetilde{C S}_{T O T}^{t}\right)$ are, respectively:

$$
\begin{aligned}
\widetilde{C S}_{H}^{t} & =\frac{77}{32} \beta^{2} \bar{u} \frac{\left(\sqrt{5 t+t^{2}+1}(2 t-2)-3 t-2 t^{2}-2\right)^{2}}{\left(2 \sqrt{5 t+t^{2}+1}-2 t-5\right)^{2}\left(2 \sqrt{5 t+t^{2}+1}+5 t+2\right)^{2}} \\
\widetilde{C S}_{L}^{t} & =\frac{49}{112} \beta^{2} \bar{u} \frac{\left(\sqrt{5 t+t^{2}+1}-t+1\right)\left(2 \sqrt{5 t+t^{2}+1}+3 t-2 t \sqrt{5 t+t^{2}+1}+2 t^{2}+2\right)}{\left(2 t-2 \sqrt{5 t+t^{2}+1}+5\right)^{2}\left(2 \sqrt{5 t+t^{2}+1}+5 t+2\right)^{2}} \\
\widetilde{C S}_{\text {TOT }}^{t} & =\frac{1}{96} \beta^{2} \bar{u} \frac{-14\left(-21 t+18 t^{2}+44 t^{3}-48\right) \sqrt{5 t+t^{2}+1}+\left(1974 t-1281 t^{2}+1792 t^{3}+616 t^{4}+672\right)}{-12(t-1)\left(3 t+2 t^{2}+2\right) \sqrt{5 t+t^{2}+1}+\left(72 t-45 t^{2}+72 t^{3}+24 t^{4}+24\right)}
\end{aligned}
$$


Similarly, for the firm-based tax scenario, they are, with $u_{L}=\widetilde{u}_{L}^{f t}$ :

$$
\begin{aligned}
\widetilde{C S}_{H}^{f t} & =2 \beta^{2} \frac{{ }^{2}\left(u_{L}+t \bar{u}\right)\left(u_{L}^{2}+\bar{u} u_{L}+t \bar{u}^{2}\right)}{\left(-u_{L}^{2}+4 \bar{u} u_{L}+4 t \bar{u}^{2}-2 t \bar{u} u_{L}\right)^{2}} \\
\widetilde{C S}_{L}^{f t} & =\beta^{2} \frac{\bar{u}^{2} u_{L}^{3}\left(\bar{u}-u_{L}\right)^{2}}{2\left(\bar{u}-u_{L}\right)^{2}\left(-u_{L}^{2}+4 \bar{u} u_{L}+4 t \bar{u}^{2}-2 \bar{u} u_{L}\right)^{2}} \\
\widetilde{C S}_{T O T}^{f t} & =\frac{1}{2} \beta^{2} \bar{u}^{2} \frac{4 \bar{u} u_{L}^{2}+4 t^{2} \bar{u}^{3}+5 u_{L}^{3}+4 t \bar{u} u_{L}^{2}+8 t \bar{u}^{2} u_{L}}{\left(-u_{L}^{2}+4 \bar{u} u_{L}+4 t \bar{u}^{2}-2 t \bar{u} u_{L}\right)^{2}}
\end{aligned}
$$

Numerical simulations show the following: ${ }^{48}$

$$
\widetilde{C S}_{H}^{t}-\widetilde{C S}_{H}^{f t}<0, \widetilde{C S}_{L}^{t}-\widetilde{C S}_{L}^{f t}>0, \widetilde{C S}_{T O T}^{t}-\widetilde{C S}_{T O T}^{f t}<0
$$

(ii) Comparing (5) with (10) and (6) with (9), we find that, for any $u_{L}$ and so, a fortiori, for the equilibrium $\frac{\widetilde{u}_{L}^{f t}}{\bar{u}} \in\left(\frac{4}{7}, 0.691\right)$ :

$$
\begin{gathered}
\tilde{\pi}_{H}^{t}-\pi_{H}^{f t}=-\frac{1}{48} \beta^{2} \bar{u} \frac{4 \bar{u}^{2}\left(20 \bar{u}^{2}-7 u_{L}^{2}-20 \bar{u} u_{L}\right) t^{2}+4 \bar{u} u_{L}\left(40 \bar{u}^{2}-7 u_{L}^{2}-54 \bar{u} u_{L}\right) t+u_{L}^{2}\left(4 \bar{u}-7 u_{L}\right)\left(20 \bar{u}+u_{L}\right)}{\left(-u_{L}^{2}+4 \bar{u} u_{L}+4 t \bar{u}^{2}-2 t \bar{u} u_{L}\right)^{2}}>0 \\
\tilde{\pi}_{L}^{t}-\pi_{L}^{f t}=\frac{1}{48} \beta^{2} \bar{u} \frac{4 \bar{u}^{2}\left(2 \bar{u}-u_{L}\right)^{2} t^{2}+4 \bar{u} u_{L}\left(8 \bar{u}^{2}+13 u_{L}^{2}-18 \bar{u} u_{L}\right) t+u_{L}^{2}\left(4 \bar{u}-7 u_{L}\right)^{2}}{\left(-u_{L}^{2}+4 \bar{u} u_{L}+4 t \bar{u}^{2}-2 t \bar{u} u_{L}\right)^{2}}>0 .
\end{gathered}
$$

\subsection{Carbon tax or green subsidies?}

\subsubsection{Proof of Proposition 3}

Proof.

$$
\tilde{E}^{t}-\tilde{E}^{s}=\frac{1}{12} \beta \frac{-4 u^{0}+2 t^{2} u^{0}-3 t^{2} \bar{u}+4 u^{0} \sqrt{5 t+t^{2}+1}-11 t u^{0}+t u^{0} \sqrt{5 t+t^{2}+1}}{t(t+4)} .
$$

From standard algebra, we get that $\tilde{E}^{t}>\tilde{E}^{s}$ for any $\frac{\bar{u}}{u^{0}}<\breve{u}(t)$ with $\breve{u}(t)=\frac{1}{3 t^{2}}\left(2 t^{2}-4+(4+t) \sqrt{5 t+t^{2}+1}-11 t\right)$ strictly less than 1 . Since

$$
\left(2 t^{2}-4+(4+t) \sqrt{5 t+t^{2}+1}-11 t\right)<0
$$

whenever $t<\bar{t}$, with $\bar{t}=0.88316$, then $\frac{\bar{u}}{u^{0}}<\breve{u}(t)$ is never satisfied if $t<\bar{t}$. Then, under the assumption that $s=t, \tilde{u}_{L}^{s}-\tilde{u}_{L}^{t}=\frac{1}{7} \bar{u} \frac{19 t-14 \sqrt{5 t+t^{2}+1}-2 t \sqrt{5 t+t^{2}+1}+2 t^{2}+14}{t+7}$.

\footnotetext{
${ }^{48} \mathrm{We}$ consider several values for $t \in(0,1)$. For a given $t$ we derive the equilibrium value of $u_{L}=u_{L}^{f t}$ from equation (18) and we proceed with the comparisons of the consumer surpluses. Details are available upon request from the authors.
} 
Notice also that $\tilde{u}_{L}^{t}-\tilde{u}_{L}^{s}=0$ in the absence of fiscal policy. Further, it holds that

$$
\frac{\partial\left(\tilde{u}_{L}^{t}-\tilde{u}_{L}^{s}\right)}{\partial t}=\frac{168 t-\left(2 t^{2}+119+28 t\right) \sqrt{5 t+t^{2}+1}+33 t^{2}+2 t^{3}+245}{(t+7)^{2} \sqrt{5 t+t^{2}+1}}<0 .
$$

So, since $\left.\tilde{u}_{L}^{s}\right|_{t=0}=\tilde{u}_{L}^{t}{ }^{{ }^{t}=0}$ and the difference $\tilde{u}_{L}^{t}-\tilde{u}_{L}^{s}$ is increasing in $t$, it immediately follows that $\tilde{u}_{L}^{t}>\tilde{u}_{L}^{s}$ for any $\left.\left.t \in\right] 0,1\right]$.

\subsubsection{Consumers and producers surplus}

When comparing consumers surplus and firms profits, it emerges that, (i) consumers surplus is higher under relative tax than under subsidy. In contrast, (ii) firms are better off when the consumers are subsidied.

Proof. Consumers surpluses under consumers taxation are provided in subsection (8.1.3). Let us define consumers surplus under relative subsidy on consumers

$$
\begin{aligned}
\widetilde{C S}_{H}^{s} & =\frac{1}{18} \beta^{2}(s+7) \bar{u} \frac{2 s+11}{(s+4)^{2}}, \\
\widetilde{C S}_{L}^{s} & =\frac{1}{72} \beta^{2} \bar{u} \frac{s+7}{s+4}, \\
\widetilde{C S}_{T O T}^{s} & =\frac{1}{24} \beta^{2} \bar{u}(s+7) \frac{3 s+16}{(s+4)^{2}} .
\end{aligned}
$$

(i) First, consider the total consumers surplus under the two scenarios.

$\widetilde{C S}_{T O T}^{t}-\widetilde{C S}_{T O T}^{s}=\frac{\bar{u} t}{288} \beta^{2} \frac{-1152 H-5184 t-806 H t^{2}+1484 H t^{3}+328 H t^{4}-2304 H t+6062 t^{2}-2043 t^{3}-2304 t^{4}-328 t^{5}-1152}{(t+4)^{2}\left(-8 H-24 t+4 H t^{2}+8 H t^{3}-4 H t+15 t^{2}-24 t^{3}-8 t^{4}-8\right)}$

with $H=\sqrt{5 t+t^{2}+1}$. Now we evaluate the numerator $\Delta$ and the denominator $\Lambda$, with $\Delta=\left(328 t^{4}+1484 t^{3}-806 t^{2}-2304 t-1152\right) H+\left(6062 t^{2}-2304 t^{4}-\right.$ $\left.2043 t^{3}-328 t^{5}-5184 t-1152\right)<0$ and $\Lambda=(t+4)^{2}\left(8 t^{3}+4 t^{2}-4 t-8\right) H+$ $\left(15 t^{2}-24 t^{3}-8 t^{4}-24 t-8\right)<0$. We conclude that

$$
\widetilde{C S}_{T O T}^{t}-\widetilde{C S}_{T O T}^{s}>0
$$

Let us compare the surpluses of consumers buying the high quality variant.

$\widetilde{C S}_{H}^{T}-\widetilde{C S}_{H}^{S}=\frac{1}{288} \beta^{2} \bar{u} \frac{\left(-9 t(31 t+184)\left(8 t^{3}+4 t^{2}-4 t-8\right)\right) \sqrt{5 t+t^{2}+1}+9 t(31 t+184)\left(8 t^{4}+24 t^{3}-15 t^{2}+24 t+8\right)}{(t+4)^{2}\left(12(1-t)\left(3 t+2 t^{2}+2\right) \sqrt{5 t+t^{2}+1}+\left(24 t^{4}+72 t^{3}-45 t^{2}+72 t+24\right)\right)}$.

After some algebraic simplifications, we get

$$
\widetilde{C S}_{H}^{T}-\widetilde{C S}_{H}^{S}=\frac{1}{96} t \beta^{2} \bar{u} \frac{31 t+184}{(t+4)^{2}}>0 .
$$


Finally, for consumers buying the low quality variant, we obtain

$$
\widetilde{C S}_{L}^{s}-\widetilde{C S}_{L}^{t}=-\frac{1}{144} \beta^{2} \bar{u} \frac{3 t\left(\left(153 t+148 t^{2}+16 t^{3}-72\right) \sqrt{t^{2}+5 t+1}-\left(27 t+481 t^{2}+188 t^{3}+16 t^{4}+72\right)\right)}{\left(12(1-t)\left(3 t+2 t^{2}+2\right)\right) \sqrt{t^{2}+5 t+1}+\left(72 t-45 t^{2}+72 t^{3}+24 t^{4}+24\right)} .
$$

Let us evaluate the denominator $\Psi$,

$\Psi=\left(-12(t-1)\left(3 t+2 t^{2}+2\right)\right) \sqrt{t^{2}+5 t+1}+\left(72 t-45 t^{2}+72 t^{3}+24 t^{4}+24\right)>0$ for any $t$, and thus $\Psi>0$ always holds. Consider now the numerator $\nabla$

$$
\nabla=\underbrace{\left(153 t+148 t^{2}+16 t^{3}-72\right) \sqrt{t^{2}+5 t+1}}_{A}-\underbrace{\left(27 t+481 t^{2}+188 t^{3}+16 t^{4}+72\right)}_{B}
$$

First notice that $B>0$ always holds. Consider the case $A-B<0$, a fortiori $A^{2}-B^{2}<0$ for any $A>0$. Otherwise, for any $A<0$, a fortiori $A-B<0$ holds. Accordingly, it is sufficient to verify that $A^{2}-B^{2}<0$ in order to prove that $A-B<0$ and thus $\nabla<0$.

$$
A^{2}-B^{2}=-21609 t^{2}(t+8)<0 \text {. }
$$

Summing up, with $\Psi>0$ and $\nabla<0$, we conclude that $\widetilde{C S}_{L}^{s}-\widetilde{C S}_{L}^{t}>0$.

(ii) $\tilde{\pi}_{H}^{t}-\tilde{\pi}_{H}^{s}=-\frac{3}{16} s \bar{u} \beta^{2} \frac{s+8}{(s+4)^{2}}<0$ and $\tilde{\pi}_{L}^{t}-\tilde{\pi}_{L}^{s}=-\frac{1}{16} s \bar{u} \frac{\beta^{2}}{s+4}<0$.

\subsubsection{Proof of Proposition 4}

Proof. We divided the proof of proposition 4 in three parts

(i) From pollution damage defined in (17), it emerges that $\frac{\partial}{\partial s} \widetilde{E}^{f s}=-\frac{1}{2} \beta \frac{u^{0}-2 \bar{u}}{(3 s+4)^{2}} \leq 0 \Longleftrightarrow u^{0}>2 \bar{u} \Longleftrightarrow \frac{\bar{u}}{u_{0}} \leq \frac{1}{2}$ : subsidizing the green firm is effective in reducing pollution emission if and only if the top environmental quality available in the market and chosen by the high quality firm is sufficiently lower than the emission-free quality benchmark.

(ii) For any given $s$, simple comparison reveals:

$\tilde{u}_{L}^{s}-\tilde{u}_{L}^{f s}=\bar{u}\left(\frac{s+4}{s+7}-\frac{3 s+4}{5 s+7}\right)=\bar{u} 2 s \frac{s+1}{(s+7)(5 s+7)}>0$.

(iii) Direct computations show, for a given $s$ equal in the two scenarios:

$$
\tilde{E}^{s}-\widetilde{E}^{f s}=-\frac{1}{2} s \beta \frac{2 u^{0}+2 s u^{0}-s \bar{u}}{(s+4)(3 s+4)}<0 .
$$




\subsubsection{Consumption versus production subsidy}

Direct comparisons show that (i) consumer surplus is higher when the subsidy is on the green producer rather than on green consumption, (ii) on the contrary, producer surplus is higher when the subsidy is on green consumption.

Proof. (i) Consumer surplus under consumer-based subsidy is defined in subsection (8.2.2). For the firm-based scenario, we define, similarly:

$$
\begin{aligned}
\widetilde{C S}_{H}^{f s} & =\beta^{2} \bar{u} \frac{\left(31 s+11 s^{2}+22\right)(s+2)(5 s+7)}{8(2 s+3)^{2}(3 s+4)^{2}}, \\
\widetilde{C S}_{L}^{f s} & =\beta^{2} \bar{u} \frac{(5 s+7)(s+1)^{2}}{8(2 s+3)^{2}(3 s+4)}, \\
\widetilde{C S}_{T O T}^{f s} & =\frac{1}{8} \beta^{2} \bar{u}(5 s+7) \frac{\left(21 s+7 s^{2}+16\right)}{(2 s+3)(3 s+4)^{2}} .
\end{aligned}
$$

Comparisons show the following:

$\widetilde{C S}_{H}^{s}-\widetilde{C S}_{H}^{f s}=-\frac{1}{72} s \beta^{2} \bar{u}(23 s+32) \frac{20 s+113 s^{2}+66 s^{3}+9 s^{4}-48}{(3 s+4)^{2}(2 s+3)^{2}(s+4)^{2}}<0 \Longleftrightarrow s>0.50498 ;$

$\widetilde{C S}_{L}^{s}-\widetilde{C S}_{L}^{f s}=-\frac{1}{72} s \beta^{2} \bar{u} \frac{344 s+197 s^{2}+33 s^{3}+186}{(s+4)(3 s+4)(2 s+3)^{2}}<0 ;$

$\widetilde{C S}_{T O T}^{s}-\widetilde{C S}_{T O T}^{f s}=-\frac{1}{24} s \beta^{2} \bar{u} \frac{784 s+954 s^{2}+411 s^{3}+51 s^{4}+160}{(2 s+3)(s+4)^{2}(3 s+4)^{2}}<0$.

(ii) As for firms, comparing profits under consumer subsidy, defined in (14) with those under firm subsidy, defined in (16), we find:

$$
\begin{aligned}
\tilde{\pi}_{H}^{s}-\tilde{\pi}_{H}^{f s} & =-\frac{1}{6} \bar{u} \beta^{2}(s+1) \frac{1424 s+1274 s^{2}+630 s^{3}+165 s^{4}+15 s^{5}+672}{(2 s+3)(s+4)^{2}(3 s+4)^{2}}<0, \\
\tilde{\pi}_{L}^{s}-\tilde{\pi}_{L}^{f s} & =\frac{1}{12} s \bar{u} \beta^{2}(s+1) \frac{3 s+2}{(3 s+4)(2 s+3)(s+4)}>0 .
\end{aligned}
$$

As for the producer surplus' comparison, $\Pi^{s}=\tilde{\pi}_{H}^{s}+\tilde{\pi}_{L}^{s}$ versus $\Pi^{f s}=\tilde{\pi}_{H}^{f s}+\tilde{\pi}_{L}^{f s}$, we find:

$$
\Pi^{s}-\Pi^{f s}=-\frac{1}{12} \bar{u} \beta^{2}(s+1) \frac{640 s+396 s^{2}+138 s^{3}+15 s^{4}+448}{(s+4)^{2}(3 s+4)^{2}}<0 .
$$

\subsection{Convex quality costs: numerical simulations}

The optimization problem of the brown firm does not vary with the introduction of convex quality costs faced by the green firm. Accordingly, we have implemented numerical simulations based on the relation between the high and low quality variants coming from the best reply function of the brown firm. Further, for sake of 
comparability, we have considered the same rate $s=t \in(0,1)$. In this analysis, $u_{H}$ is assumed to be in the interval $(0.1,10)$, while different values have been attributed to the parameters of the model (i.e. $\beta, s$ and $t$ ). More in detail, from a uniform distribution (i.e. $u_{H} \sim U(0.1,10)$ ), we have drawn randomly $500 u_{H}$-values which profile the profits curve trend. Among these $u_{H}$-values, we have selected those which are profit maximizing for any couple of $\beta, t$ values. The maximal WTP $\beta$ takes the following values $\beta=[2,4,6,8,10]$ while the tax/subsidy rate is assumed to be $t=[0.2,0.4,0.6,0.8]$. For the comparisons of the pollution damages in the different scenarios, we assume $\bar{u}=10$, so that $u^{0} \geq 10$. Here, results of numerical simulation are presented consistently with the structure of the model with qualityspecific fixed production cost. Details on numerical results are provided in Annex I: optimal qualities are reported in Table I while firm's profits and pollution damage are respectively in Table II and Table III.

First, when considering convex quality costs on the green variant, $\tilde{u}_{L}^{t}$ is still increasing in $t$. Further, the fiscal plan does not have any impact on firms profits. Also, the benefit of taxing brown consumption in terms of environmental quality is robust to this alternative specification of production costs.

In particular, from the comparison between taxation on consumers and producers, numerical simulations show that $\tilde{u}_{L}^{t}>\tilde{u}_{L}^{f t}$ is always verified for any couple of $\beta, t$-values, as in the corresponding model with fixed costs. Moreover, we find that, in line with the baseline model, pollution damage under production tax can be higher than the corresponding tax on consumers, namely $\tilde{E}^{f t}>\tilde{E}^{t}$. Whenever the ratio between the optimal qualities and the emission-free quality - when this latter is set at its minimum value - is relatively low, (i.e. $\max \left\{\frac{\tilde{u}^{f t}}{u^{0}}, \frac{\tilde{u}^{t}}{u^{0}}\right\}<0.527$ with $u^{0}=\bar{u}=10$ ), we observe $\tilde{E}^{f t}>\tilde{E}^{t}$. Notice that this occurs for $\beta \leq 6$, irrespective of the tax rate. However when both $\frac{\tilde{u}^{f t}}{u^{0}}$ and $\frac{\tilde{u}^{t}}{u^{0}}$ are closer to 1 , namely the distance between the optimal qualities and the emission-free quality is relatively small, the reverse holds and thus $\tilde{E}^{f t}<\tilde{E}^{t}$. However, if we allow for a higher value of $u^{0}$, for example $u^{0}>21.604$, a relative tax on brown producers always leads to larger pollution damage than in case of consumers taxation.

Concerning profits, irrespective of the $\beta, t$-values, we observe $\tilde{\pi}_{L}^{t}>\tilde{\pi}_{L}^{f t}$ with $\tilde{\pi}_{L}^{f t}$ decreasing in $t$, and $\tilde{\pi}_{H}^{t}>\tilde{\pi}_{H}^{f t}$ holds for relatively low value of $t$ (i.e. $t<0.6$ ).

From the comparison between consumer-based fiscal measures, it emerges that the brown quality is higher under tax than under subsidy for relatively high values of $\beta$. This is rather reasonable, since the role of quality-dependent convex cost is 
mitigated by the highest WTP.

Concerning the pollution damage, a relative subsidy on consumption results in a larger pollution damage than taxation for a high value of $\beta$ or for low values of both $\beta$ and subsidy/tax rate; indeed $\tilde{E}^{s}>\tilde{E}^{t}$ always holds when $\beta=10$ or $\beta=2$ with $t=0.2$ or $t=0.4$. For the other $\beta, t$ values, the result strictly depends on the difference $\left(u^{0}-u_{H}\right)$ : increasing values of this difference result in a wider range of parameters for which $\tilde{E}^{s}>\tilde{E}^{t}$ is observed.

For sake of completeness, we have compared the two alternative scenarios on green subsidy, namely (i) green subsidy on consumers vsus green subsidy on producer and (ii) taxation on producer vsus subsidy on producer.

As far as the former scenario is concerned, when evaluating a green subsidy on consumers and producers, simulations show that $\tilde{u}_{L}^{s}>\tilde{u}_{L}^{f s}$ and $\tilde{E}^{f s}>\tilde{E}^{s}$ are always verified, consistently with the analysis in the baseline model.

As for the latter case, when comparing the firm-based measures, it emerges that the low quality variant is higher under taxation than in case of green subsidies on producers for a relatively high (resp. low) value of $\beta$, namely $\tilde{u}_{L}^{f t}>\tilde{u}_{L}^{f s}$ (resp. lower, $\left.\tilde{u}_{L}^{f s}>\tilde{u}_{L}^{f t}\right)$, regardless of the tax rate. For the pollution damage, $\tilde{E}^{f s}>\tilde{E}^{f t}$ holds in the following cases: $\beta=(2 ; 10), \beta=4$ with $t=0.2$ and $t=0.6$ and $\beta=8$ with $t=(0.4 ; 0.6 ; 0.8)$. For all the remaining cases, the ranking depends on the value of $u^{0}$ : when $u^{0}$ is larger, the range of parameters such that $\tilde{E}^{f s}>\tilde{E}^{f t}$ holds increases. 
Annex I, Table I

Optimal qualities

$\beta=$ consumers' willingness to pay; $t=\operatorname{tax} /$ subsidy rate; $\tilde{u}_{H}^{t}=$ high quality under relative taxation on brown consumption; $\tilde{u}_{L}^{t}=$ low quality under relative taxation on brown consumption; $\tilde{u}_{H}^{f t}=$ high quality under relative taxation on brown production; $\tilde{u}_{L}^{f t}=$ low quality under relative taxation on brown production; $\tilde{u}_{H}^{s}=$ high quality under relative subsidy on green consumption; $\tilde{u}_{L}^{s}=$ low quality under relative subsidy on brown production; $\tilde{u}_{H}^{s f}=$ high quality under relative subsidy on green production; $\tilde{u}_{L}^{s f}=$ low quality under relative subsidy on green production.

\begin{tabular}{c|cccccccc}
\hline$(\beta, t)$ & $\tilde{u}_{H}^{t}$ & $\tilde{u}_{L}^{t}$ & $\tilde{u}_{H}^{f t}$ & $\tilde{u}_{L}^{f t}$ & $\tilde{u}_{H}^{s}$ & $\tilde{u}_{L}^{s}$ & $\tilde{u}_{H}^{f s}$ & $\tilde{u}_{L}^{f s}$ \\
\hline$(2,0.2)$ & 0.578 & 0.368 & 0.581 & 0.362 & 0.650 & 0.379 & 0.646 & 0.371 \\
$(2,0.4)$ & 0.578 & 0.393 & 0.590 & 0.384 & 0.715 & 0.425 & 0.701 & 0.405 \\
$(2,0.6)$ & 0.578 & 0.411 & 0.588 & 0.393 & 0.753 & 0.456 & 0.765 & 0.444 \\
$(2,0.8)$ & 0.578 & 0.425 & 0.581 & 0.396 & 0.812 & 0.500 & 0.823 & 0.479 \\
$(4,0.2)$ & 2.329 & 1.482 & 2.319 & 1.444 & 2.622 & 1.520 & 2.586 & 1.487 \\
$(4,0.4)$ & 2.329 & 1.821 & 2.331 & 1.516 & 2.855 & 1.697 & 2.826 & 1.633 \\
$(4,0.6)$ & 2.329 & 1.655 & 2.306 & 1.541 & 3.075 & 1.861 & 3.061 & 1.776 \\
$(4,0.8)$ & 2.329 & 1.713 & 2.336 & 1.591 & 3.250 & 2.000 & 3.298 & 1.919 \\
$(6,0.2)$ & 5.252 & 3.343 & 5.217 & 3.250 & 5.870 & 3.424 & 5.813 & 3.342 \\
$(6,0.4)$ & 5.252 & 3.567 & 5.237 & 3.406 & 6.436 & 3.826 & 6.357 & 3.673 \\
$(6,0.6)$ & 5.252 & 3.733 & 5.247 & 3.507 & 6.912 & 4.183 & 6.893 & 3.998 \\
$(6,0.8)$ & 5.252 & 3.864 & 5.273 & 3.592 & 7.323 & 4.506 & 7.416 & 4.315 \\
$(8,0.2)$ & 9.327 & 5.938 & 9.293 & 5.789 & 9.937 & 5.797 & 9.999 & 5.750 \\
$(8,0.4)$ & 9.327 & 6.336 & 9.286 & 6.040 & 9.937 & 5.909 & 9.999 & 5.778 \\
$(8,0.6)$ & 9.327 & 6.630 & 9.332 & 6.237 & 9.937 & 6.015 & 9.999 & 5.800 \\
$(8,0.8)$ & 9.327 & 6.861 & 9.374 & 6.385 & 9.937 & 6.115 & 9.999 & 5.818 \\
$(10,0.2)$ & 9.327 & 6.326 & 9.998 & 6.228 & 9.937 & 5.797 & 9.999 & 5.750 \\
$(10,0.4)$ & 9.327 & 6.750 & 9.962 & 6.480 & 9.937 & 5.909 & 9.999 & 5.778 \\
$(10,0.6)$ & 9.327 & 7.064 & 9.984 & 6.674 & 9.937 & 6.015 & 9.999 & 5.800 \\
$(10,0.8)$ & 9.327 & 7.311 & 9.989 & 6.804 & 9.937 & 6.115 & 9.999 & 5.818 \\
\hline
\end{tabular}


Annex I, Table II

Firms'profits

$\beta=$ Consumers' willingness to pay; $t=$ Tax/Subsidy rate; $\tilde{\pi}_{H}^{t}=$ profit of firm $\mathrm{H}$ under relative taxation on brown consumption; $\tilde{\pi}_{L}^{t}=$ profit of firm $\mathrm{L}$ under relative taxation on brown consumption; $\tilde{\pi}_{H}^{f t}=$ profit of firm $\mathrm{L}$ under relative taxation on brown production; $\tilde{\pi}_{L}^{f t}=$ profit firm L under relative taxation on brown production; $\tilde{\pi}_{H}^{s}=$ profit of firm $\mathrm{H}$ under relative subsidy on green consumption; $\tilde{\pi}_{L}^{s}=$ profit of firm L under relative subsidy on brown production; $\tilde{\pi}_{H}^{s f}=$ profit of firm $\mathrm{H}$ under relative subsidy on green production; $\tilde{\pi}_{L}^{s f}=$ profit of firm L under relative subsidy on green production.

\begin{tabular}{c|cccccccc}
\hline$(\beta, t)$ & $\tilde{\pi}_{H}^{t}$ & $\tilde{\pi}_{L}^{t}$ & $\tilde{\pi}_{H}^{f t}$ & $\tilde{\pi}_{L}^{f t}$ & $\tilde{\pi}_{H}^{s}$ & $\tilde{\pi}_{L}^{s}$ & $\tilde{\pi}_{H}^{s f}$ & $\tilde{\pi}_{L}^{s f}$ \\
\hline$(2,0.2)$ & 0.170 & 0.048 & 0.168 & 0.040 & 0.213 & 0.062 & 0.209 & 0.060 \\
$(2,0.4)$ & 0.170 & 0.048 & 0.169 & 0.035 & 0.255 & 0.076 & 0.249 & 0.070 \\
$(2,0.6)$ & 0.170 & 0.048 & 0.170 & 0.030 & 0.293 & 0.087 & 0.293 & 0.080 \\
$(2,0.8)$ & 0.170 & 0.048 & 0.172 & 0.027 & 0.330 & 0.102 & 0.339 & 0.091 \\
$(4,0.2)$ & 2.722 & 0.776 & 2.690 & 0.634 & 3.412 & 0.999 & 3.337 & 0.953 \\
$(4,0.4)$ & 2.722 & 0.776 & 2.703 & 0.546 & 4.073 & 1.211 & 3.991 & 1.121 \\
$(4,0.6)$ & 2.722 & 0.776 & 2.724 & 0.474 & 4.697 & 1.426 & 4.688 & 1.287 \\
$(4,0.8)$ & 2.722 & 0.776 & 2.746 & 0.429 & 5.281 & 1.625 & 5.430 & 1.452 \\
$(6,0.2)$ & 13.781 & 3.939 & 13.616 & 3.209 & 17.273 & 5.032 & 16.893 & 4.817 \\
$(6,0.4)$ & 13.781 & 3.939 & 13.683 & 2.759 & 20.618 & 6.143 & 20.205 & 5.675 \\
$(6,0.6)$ & 13.781 & 3.939 & 13.790 & 2.426 & 23.777 & 7.213 & 23.734 & 6.520 \\
$(6,0.8)$ & 13.781 & 3.939 & 13.899 & 2.177 & 26.736 & 8.238 & 27.491 & 7.346 \\
$(8,0.2)$ & 43.556 & 12.436 & 43.032 & 10.163 & 54.460 & 15.143 & 53.334 & 14.731 \\
$(8,0.4)$ & 43.556 & 12.436 & 43.245 & 8.696 & 64.069 & 16.863 & 63.011 & 15.870 \\
$(8,0.6)$ & 43.556 & 12.436 & 43.582 & 7.672 & 72.453 & 18.435 & 72.484 & 16.814 \\
$(8,0.8)$ & 43.556 & 12.436 & 43.928 & 6.881 & 79.810 & 19.875 & 81.819 & 17.608 \\
$(10,0.2)$ & 95.544 & 20.703 & 94.944 & 17.084 & 112.867 & 23.660 & 111.456 & 23.017 \\
$(10,0.4)$ & 95.544 & 20.703 & 95.141 & 14.577 & 127.882 & 26.349 & 126.577 & 24.797 \\
$(10,0.6)$ & 95.544 & 20.703 & 95.806 & 12.825 & 140.981 & 28.804 & 141.378 & 26.272 \\
$(10,0.8)$ & 95.544 & 20.703 & 96.404 & 11.457 & 152.477 & 31.054 & 155.965 & 27.512 \\
\hline & & & & & & & &
\end{tabular}


Annex I, Table III

Pollution damage

$\beta=$ consumers' willingness to pay; $t=\operatorname{tax} /$ subsidy rate; $\tilde{E}^{t}=$ pollution damage under relative taxation on brown consumption; $\tilde{E}^{f t}=$ pollution damage under relative taxation on brown production; $\tilde{E}^{s}=$ pollution damage under relative subsidy on green consumers; $\tilde{E}^{f s}=$ pollution damage under relative subsidy on green production.

\begin{tabular}{c|cccc}
\hline$(\beta, t)$ & $\tilde{E}^{t}$ & $\tilde{E}^{f t}$ & $\tilde{E}^{s}$ & $\tilde{E}^{f s}$ \\
\hline$(2,0.2)$ & $1.690 u^{0}-0.867$ & $1.709 u^{0}-0.890$ & $1.714 u^{0}-0.960$ & $1.739 u^{0}-0.955$ \\
$(2,0.4)$ & $1.657 u^{0}-0.867$ & $1.689 u^{0}-0.914$ & $1.682 u^{0}-1.040$ & $1.731 u^{0}-1.024$ \\
$(2,0.6)$ & $1.636 u^{0}-0.867$ & $1.676 u^{0}-0.918$ & $1.652 u^{0}-1.080$ & $1.724 u^{0}-1.108$ \\
$(2,0.8)$ & $1.620 u^{0}-0.867$ & $1.667 u^{0}-0.911$ & $1.625 u^{0}-1.150$ & $1.719 u^{0}-1.183$ \\
$(4,0.2)$ & $3.381 u^{0}-6.987$ & $3.419 u^{0}-7.107$ & $3.429 u^{0}-7.742$ & $3.478 u^{0}-7.647$ \\
$(4,0.4)$ & $3.315 u^{0}-6.987$ & $3.378 u^{0}-7.221$ & $3.364 u^{0}-8.305$ & $3.461 u^{0}-8.260$ \\
$(4,0.6)$ & $3.271 u^{0}-6.987$ & $2.240 u^{0}-5.408$ & $3.304 u^{0}-8.824$ & $3.448 u^{0}-8.867$ \\
$(4,0.8)$ & $3.240 u^{0}-6.987$ & $3.334 u^{0}-7.326$ & $3.250 u^{0}-9.208$ & $3.437 u^{0}-9.483$ \\
$(6,0.2)$ & $5.071 u^{0}-23.633$ & $5.128 u^{0}-23.982$ & $5.143 u^{0}-25.997$ & $5.217 u^{0}-25.778$ \\
$(6,0.4)$ & $4.972 u^{0}-23.633$ & $5.066 u^{0}-24.340$ & $5.045 u^{0}-28.084$ & $5.192 u^{0}-27.874$ \\
$(6,0.6)$ & $4.907 u^{0}-23.633$ & $5.028 u^{0}-24.558$ & $4.957 u^{0}-29.754$ & $5.172 u^{0}-29.949$ \\
$(6,0.8)$ & $4.859 u^{0}-23.633$ & $5.002 u^{0}-24.802$ & $4.875 u^{0}-31.122$ & $5.156 u^{0}-31.983$ \\
$(8,0.2)$ & $6.761 u^{0}-55.962$ & $6.838 u^{0}-56.962$ & $6.857 u^{0}-58.678$ & $6.956 u^{0}-59.128$ \\
$(8,0.4)$ & $6.629 u^{0}-55.962$ & $6.755 u^{0}-57.547$ & $6.727 u^{0}-57.817$ & $6.923 u^{0}-58.459$ \\
$(8,0.6)$ & $6.542 u^{0}-55.962$ & $6.704 u^{0}-58.236$ & $6.609 u^{0}-57.032$ & $6.897 u^{0}-57.929$ \\
$(8,0.8)$ & $6.479 u^{0}-55.962$ & $6.669 u^{0}-58.786$ & $6.500 u^{0}-56.312$ & $6.875 u^{0}-57.498$ \\
$(10,0.2)$ & $8.451 u^{0}-74.531$ & $8.547 u^{0}-76.605$ & $8.571 u^{0}-73.347$ & $8.6957 u^{0}-73.91$ \\
$(10,0.4)$ & $8.287 u^{0}-74.530$ & $8.444 u^{0}-77.170$ & $8.409 u^{0}-72.272$ & $8.654 u^{0}-73.074$ \\
$(10,0.6)$ & $8.178 u^{0}-74.530$ & $8.380 u^{0}-77.883$ & $8.261 u^{0}-71.290$ & $8.621 u^{0}-72.411$ \\
$(10,0.8)$ & $8.099 u^{0}-74.530$ & $8.336 u^{0}-78.305$ & $8.125 u^{0}-70.390$ & $8.594 u^{0}-71.872$ \\
\hline & & & &
\end{tabular}




\section{References}

[1] Allcott, H. (2011). Social norms and energy conservation. Journal of Public Economics, 95(9), 1082-1095.

[2] André, F. J., González P. and N. Porteiro (2009). Strategic quality competition and the Porter Hypothesis. Journal of Environmental Economics and Management, 57 (2), 182-194.

[3] Arrow, K. (1970). Political and economic evaluation of social effects and externalities. In: The analysis of public output. NBER, 1-30.

[4] Bansal, S. and S. Gangopadhyay (2003). Tax/subsidy policies in the presence of environmentally aware consumers. Journal of Environmental Economics and Management, 45(2), 333-355.

[5] Ben Elhadj, N. and O. Tarola (2015). Relative quality-related (dis)utility in vertically differentiated oligopoly with an environmental externality. Environment and Development Economics, 20 (3) 354-379.

[6] Böhringer, C., Rosendahl, K. E., and, H. B. Storrøsten (2017). Robust policies to mitigate carbon leakage. Journal of Public Economics, 149, 35-46.

[7] Brécard, D. (2013). Environmental quality competition and taxation in the presence of green network effect among consumers. Environmental and Resource Economics, 54(1), 1-19.

[8] Brekke, K. A., Kverndokk, S. and K. Nyborg (2003). An economic model of moral motivation. Journal of Public Economics, 87(9), 1967-1983.

[9] Carlsson, F., Garcia, J. and A. Löfgren (2010). Conformity and the Demand for Environmental Goods. Environmental and Resource Economics, 47 (3), 407 421.

[10] Carrington, M. J., Neville B. A. and G. J. Whitwell (2010). Why ethical consumers don't walk their talk: Towards a framework for understanding the gap between the ethical purchase intentions and actual buying behaviour of ethically minded consumers. Journal of Business Ethics, 97(1), 139-158.

[11] Choi, C. J. and H. S. Shin (1992). A comment on a model of vertical product differentiation. The Journal of Industrial Economics, 229-231. 
[12] Cremer, H. and J. F. Thisse (1999). On the taxation of polluting products in a differentiated industry. European Economic Review, 43(3), 575-594.

[13] Czajkowski, M., Hanley, N. and K. Nyborg (2015). Social norms, morals and self-interest as determinants of pro-environment behaviours: the case of household recycling. Environmental and Resource Economics, 1-24.

[14] Elster, J. (1989). Social Norms and Economic Theory. The Journal of Economic Perspectives, 3(4), 99-117.

[15] Finisterra do Paço, A. M., Barata Raposo, M. L. and L. Walter Filho (2009). Identifying the green consumer: A segmentation study. Journal of Targeting, Measurement and Analysis for Marketing, 17(1), 17-25.

[16] Frondel, M., Horbach J. and K. Rennings (2007). End-of-pipe or cleaner production? An empirical comparison of environmental innovation decisions across OECD countries. Business Strategy and the Environment, 16(8), 571-584.

[17] Gabszewicz, J. J. and J. F. Thisse (1979). Price competition, quality and income disparities. Journal of Economic Theory, 20 (3), 340-359.

[18] Galinato, G. I. and J. K. Yoder. (2010). An integrated tax-subsidy policy for carbon emission reduction. Resource and Energy Economics 32 (3), 310-326.

[19] García-Gallego, A. and N. Georgantzís (2009). Market effects of changes in consumers' social responsibility. Journal of Economics \& Management Strategy, 18(1), 235-262.

[20] Gerlagh, R., Kverndokk S. and K. E. Rosendahl (2009). Optimal timing of climate change policy: Interaction between carbon taxes and innovation externalities. Environmental and Resource Economics 43(3), 369-390.

[21] Greaker, M. and K. Midttømme (2016). Network effects and environmental externalities: Do clean technologies suffer from excess inertia? Journal of Public Economics, 143, 27-38.

[22] Grilo, I. O. Shy and J. Thisse (2001). Price competition when consumer behaviour is characterized by conformity or vanity. Journal of Public Economics, 80: 385-408. 
[23] Gupta, S., and Ogden, D. T. (2009). To buy or not to buy? A social dilemma perspective on green buying. Journal of Consumer Marketing, 26(6), 376-391.

[24] Ikefuji, M., Itaya J. I. and M. Okamura (2016). Optimal emission tax with endogenous location choice of duopolistic firms. Environmental and Resource Economics, 65(2), 463-485.

[25] Koonsed P. (2015) Optimal policy under duopoly with environmental quality. Economics Bulletin 35 (3),1976-1984.

[26] Lambertini, L. (2013). Oligopoly, the environment and natural resources. Routlegde.

[27] Lombardini-Riipinen C. (2005). Optimal Tax Policy under Environmental Quality Competition. Environmental and Resource Economics, 32 (3), 317-336.

[28] Mantovani, A., Tarola O. and C. Vergari (2016). Hedonic and environmental quality: A hybrid model of product differentiation. Resource and Energy Economics, 45, 99-123.

[29] Mantovani, A., Tarola O. and C. Vergari (2017). End-of-pipe or cleaner production? How to go green in presence of income inequality and pro-environmental behavior. Journal of Cleaner Production. Forthcoming.

[30] Mantovani, A. and C. Vergari (2017). Environmental vs Hedonic Quality: Which Policy Can Help in Lowering Pollution Emissions? Environment and Development Economics, forthcoming.

[31] Mondelaers, K., Aertsens, J. and G. Van Huylenbroeck (2009). A meta-analysis of the differences in environmental impacts between organic and conventional farming. British food journal, 111(10), 1098-1119.

[32] Moraga-Gonzalez, J. L. and N. Padron-Fumero (2002). Environmental Policy in a Green Market. Environmental and Resource Economics, 22 (3), 419-447.

[33] Mussa, M. and S. Rosen (1978). Monopoly and product quality. Journal of Economic theory, 18(2), 301-317.

[34] National Geographic and Globescan (2014). Greendex 2014: Consumers choice and the Environment- A Worldwide Tracking Survey. 
[35] Ostrom, E. (2000). Collective Action and the Evolution of Social Norms. The Journal of Economic Perspectives, 14 (3), 137-158.

[36] Owen, A. L. and J.R. Videras (2007). Culture and public goods: The case of religion and the voluntary provision of environmental quality. Journal of Environmental Economics and Management, 54(2), 162-180.

[37] Petrakis, E. and A. Xepapadeas (2003). Location decisions of a polluting firm and the time consistency of environmental policy. Resource and Energy Economics, 25(2), 197-214.

[38] Porter, M. E. (1991). America's Green Strategy, in: Scientific American, 264 (4), 168 .

[39] Rodriguez-Ibeas R. (2007). Environmental Product differentiation and Environmental Awareness. Environmental and Resource Economics 36, 237-254.

[40] Salazar, H.A., L. Oerlemans, and S. van Stroe-Biezen (2013). 'Social influence on sustainable consumption: evidence from a behavioural experiment', International Journal of Consumer Studies, 37(2): 172-180.

[41] Sanna-Randaccio, F., Sestini R. and O. Tarola (2016). Unilateral climate policy and foreign direct investment with firm and country heterogeneity. Environmental and Resource Economics, 1-23.

[42] Tuomisto, H. L., Hodge, I. D., Riordan, P. and D. W. Macdonald (2012). Does organic farming reduce environmental impacts?-A meta-analysis of European research. Journal of Environmental Management, 112, 309-320.

[43] Veblen, T. (1899). Theory of the Leisure Class: An Economic Study in the Evolution of Institutions. New York: Macmillan.

[44] Videras, J., Owen, A. L., Conover, E. and S. Wu (2012). The influence of social relationships on pro-environment behaviors. Journal of Environmental Economics and Management, 63(1), 35-50.

[45] Welsch,H. and J. Kuhling (2009). Determinants of pro-environmental consumption: the role of reference groups and routine behavior, Ecological Economics (69) 166-176. 
[46] Xepapadeas, A. and A. de Zeeuw (1999). Environmental policy and competitiveness: the Porter hypothesis and the composition of capital. Journal of Environmental Economics and Management, 37(2), 165-182. 


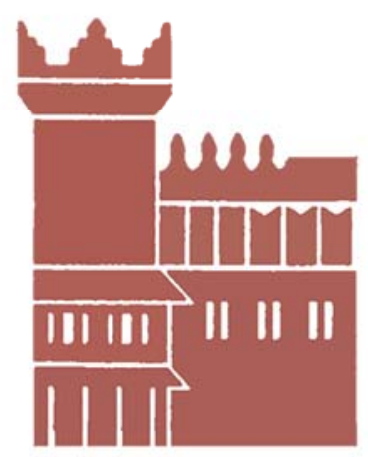

Alma Mater Studiorum - Università di Bologna DEPARTMENT OF ECONOMICS

Strada Maggiore 45

40125 Bologna - Italy

Tel. +39051 2092604

Fax +390512092664

http://www.dse.unibo.it 